\title{
Primeras determinaciones radiocarbónicas de la necrópolis de Setefilla (Lora del Río) y el inicio del periodo orientalizante en Andalucía occidental*
}

\author{
First radiocarbon determinations from the Setefilla necropolis (Lora del Rí) and the \\ beginning of the Orientalizing period in western Andalusia
}

\author{
Dirk Brandherm ${ }^{\mathrm{a}}$ y Michał Krueger ${ }^{\mathrm{b}}$
}

\section{RESUMEN}

Se presenta una amplia serie de nuevas determinaciones radiocarbónicas sobre hueso cremado, procedentes en su mayoría de las tumbas de los túmulos A y B de Setefilla, pero también de otros yacimientos del sur y oeste de la Península Ibérica. Se discute el potencial que aportan para resolver cuestiones de la cronología interna de la necrópolis y de su relación cronológica con el poblado de la Mesa de Setefilla, así como sus repercusiones generales sobre la cronología del Bronce Final y Hierro Antiguo en el Sudoeste peninsular.

\begin{abstract}
We present a sizeable series of new radiocarbon determinations of cremated bone samples, mainly from barrows $A$ and $B$ at Setefilla, but also from a number of other sites in the southern and western Iberian Peninsula. We discuss the potential they hold for refining the internal chronology of the Setefilla necropolis, for addressing its chronological relationship with the Mesa de Setefilla settlement site, and for changing our understanding of Late Bronze Age and Early Iron Age chronology in southwestern Iberia.
\end{abstract}

Palabras claves: Bronce Final; Hierro Antiguo; Radiocarbono; Cronología; Ritual funerario; Mediterráneo occidental.

Key words: Late Bronze Age; Early Iron Age; Radiocarbon; Chronology; Funerary ritual; Western Mediterranean.

\section{INTRODUCCIÓN}

El yacimiento de Setefilla está ubicado en la orilla derecha del arroyo Guadalbacar, uno de los afluentes del río Guadalquivir (Fig. 1). Comprende un longevo poblado fundado en el Bronce Medio ${ }^{1}$ y una extensa necrópolis ubicada a unos 900 m en línea recta del mismo, cuya ocupación principal se adscribe al Hierro Antiguo. El poblado se encuentra en el extremo septentrional de la Mesa de Setefilla, una meseta que forma parte de las estribaciones meridionales de Sierra Morena. Sobre la Mesa en la actualidad existen una ermita y las ruinas de un castillo medieval.

* Esta investigación ha sido financiada por el proyecto "La Edad del Hierro Inicial en la zona suroccidental de la Península Ibérica: cronología y cultura material" del Centro Nacional Polaco de la Ciencia (Narodowe Centrum Nauki - NCN), concedido de acuerdo con el convenio DEC-2013/09/B/HS3/00630.

${ }^{a}$ Queen's University Belfast. School of Natural and Built Environment. Belfast, BT7 1NN Irlanda del Norte. Reino Unido. Correo e.: d.brandherm@qub.ac.uk http://orcid.org/0000-0003-3171-6370.

b Uniwersytet im. Adama Mickiewicza w Poznaniu. Instytut Archeologii. ul. Umultowska 89D, 61-614 Poznań. Polonia. Correo e.: krueger@amu.edu.pl http://orcid.org/0000-0002-2607-2825.

Recibido 5-XII-2016; aceptado 25-IV-2017.

1 Preferimos evitar el término "Bronce Pleno", habitual en la bibliografía sobre el yacimiento, por su carácter poco preciso (cf. Roberts et al. 2013: 37). 


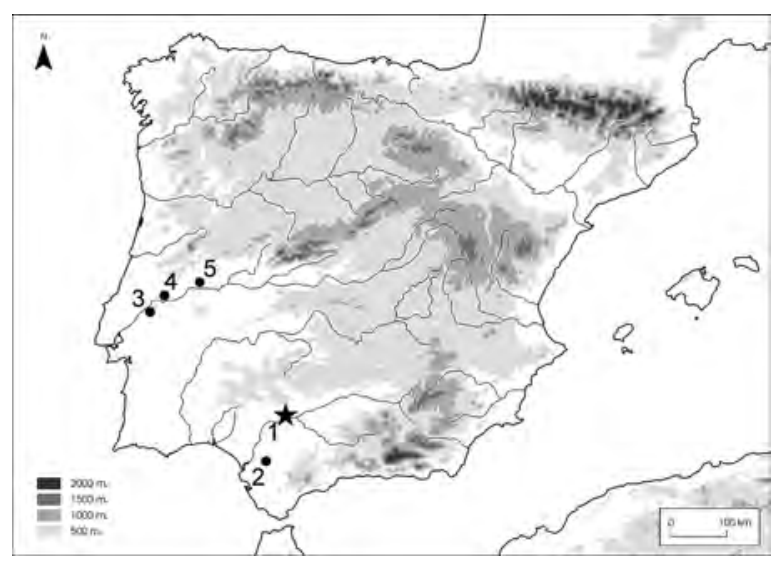

Fig. 1. Localización en la Península Ibérica de los yacimientos mencionados en el texto: 1. Setefilla (Lora del Río, Sevilla); 2. Rabadanes (Las Cabezas de San Juan, Sevilla); 3. Tanchoal dos Patudos (Alpiarça, Santarém); 4. Souto (Abrantes, Santarém); 5. Monte de São Domingos (Malpica do Tejo, Castelo Branco).

La localización geográfica permitía controlar el tráfico en el valle del Guadalquivir y facilitaba acceso al interior de la Península Ibérica a través de la Sierra Morena. La necrópolis, próxima al poblado pero al exterior de la Mesa, consta de unos catorce túmulos conocidos y varias tumbas aisladas, fuera del ámbito de los túmulos, cuyo número exacto se desconoce ${ }^{2}$.

Setefilla con su poblado y necrópolis asociada es uno de los yacimientos emblemáticos de la llamada "cultura tartésica" a la que nos referiremos como "Complejo Orientalizante del Suroeste" (COSO) (un resumen del debate terminológico en Brandherm 2016: 180-183). Durante el siglo XX Setefilla fue objeto de varias intervenciones arqueológicas, sobre todo por parte de Jorge Bonsor y María Eugenia Aubet. La cantidad de datos que han aportado las excavaciones realizadas en la necrópolis, junto con el detallado estudio tipológico y cuantitativo de los materiales convierten este yacimiento en un sitio clave para abarcar un amplio abanico de cuestiones relacionadas con el

\footnotetext{
2 Según Bonsor y Thouvenot (1928: 31-35, también fig. 4) había 5 tumbas prerromanas y 6 romanas pero esta información puede ser imprecisa. La delimitación de los túmulos por los primeros excavadores no siempre fue correcta y, en opinión de Aubet (1997: 165), se mezclaron gran número de materiales. Además, Bonsor y Thouvenot no exploraron toda el área arqueológica por lo que cabe suponer que haya más tumbas individuales en la necrópolis de Setefilla.
}

COSO. Desde los inicios de los trabajos resultaba problemático establecer la cronología de las tumbas a partir de la estratigrafía y la tipología de los artefactos. Este trabajo intenta resolver algunos de esos problemas básicos relacionados con la necrópolis de Setefilla. Dado el objetivo de este estudio no se contarán las tumbas ibéricas ni romanas, que tambíen se han documentado en la necrópolis (Aubet 1975: 129-133; Aubet 1978: 216-219).

\section{HISTORIA DE LAS INVESTIGACIONES}

El yacimiento de Setefilla era conocido ya en el siglo XVIII (Maier 1999: 274). Jorge Bonsor, intentando encontrar la antigua Axati, exploró la zona de la Mesa de Setefilla en 1889. De la segunda excursión, emprendida en 1901, proviene su descripción (Bonsor 1931) del conjunto arqueológico de Setefilla (Maier 1999: 274). Entre 1926 y 1927 J. Bonsor y su ayudante Raymond Thouvenot excavaron en la necrópolis. Correctamente la adscribió a la llamada cultura tartésica $\mathrm{y}$, basándose en las importaciones de carácter oriental, estableció su cronología entre los siglos VII-VI a.C. M. ${ }^{a}$ E. Aubet (1973) estudió los materiales de esas excavaciones que se salvaron de la guerra civil española y en 1973 empezó a excavar el túmulo A (Aubet 1975). La segunda campaña de 1975 se centró en el túmulo B (Aubet 1978; también 1976, 1980-81, 1982a, 1982b para una visión global de los resultados de las excavaciones en la necrópolis) ${ }^{3}$.

Los sondeos se realizaron en la Mesa del Castillejo y la Mesa de Setefilla entre 1975-1979 (Aubet et al. 1983; Aubet 1989). Estos trabajos establecieron una secuencia ininterrumpida desde

\footnotetext{
3 Destacamos entre los estudios inéditos sobre la necrópolis de Setefilla: Czarnetzki, A. s/a: Die Leichenbrandreste aus dem Tumulus $A$ und $B$ von Setefilla, Andalusien. Informe inédito, Universitat Pompeu Fabra. Barcelona

Izquierdo Egea, P. 1989: El horizonte orientalizante en el Mediterráneo occidental. Aproximación a la reconstrucción económica y social de las comunidades tartésicas de los ss. VIII-VI a.C. Trabajo de Investigación de Doctorado inédito, Universitat Autónoma de Barcelona. Bellaterra;

Delgado Hervás, A. 2002: De guerreros a comerciantes: poder e intercambio en las comunidades del Bronce Final de Andalucía occidental. Tesis doctoral, Universitat Pompeu Fabra. Barcelona.
} 
el Bronce Medio hasta el periodo ibérico y demostraron la relación entre el poblado y la necrópolis.

En los años 1990 varios estudios se basaron en los materiales arqueológicos y antropológicos de Setefilla, destacando los de Aubet (1995), Aubet et al. (1996) y Torres (1996). Krueger $\left({ }^{4}, 2016\right)$ estudió las cuestiones sociales relacionadas con la comunidad de Setefilla. Setefilla era también uno de los yacimientos claves del proyecto que ha financiado el presente trabajo.

\section{LAS ESTRUCTURAS FUNERARIAS DEL TÚMULO A}

En el túmulo A $(28 \mathrm{~m} \times 29 \mathrm{~m})$ se localizaron 66 tumbas: 41 en la necrópolis de base, 4 depositadas en la fase de la construcción de la cámara funeraria o poco después, la propia cámara funeraria que, aunque apareciera vacía es el monumento funerario por excelencia, y 20 tumbas localizadas por encima de la necrópolis de base, pero aun no en el relleno. Es de suponer que en el mismo hubiera varias decenas de tumbas desbaratadas.

La fase I, la necrópolis de base, cuenta con 41 tumbas que van de la A15 a la A23, de la A25 a la A34, de la A41 a la A57 y de la A61 a la A65. Salvo la A49, externa al círculo funerario, todas fueron depositadas en/o sobre un suelo rocoso en un área circular rodeada por diez losas hincadas. Durante la fase pretumular del monumento el círculo funerario se asemeja en cierto modo a otros monumentos funerarios del Bronce Final y de inicios del Hierro Antiguo en el sur y oeste peninsular (Cruz 1997: 89 fig. 2; Lorrio 2008: 366 fig. 198, 199; Brandherm 2016: 194-195). Además de su delimitación por losas hincadas, la falta de fosas cavadas en la roca al exterior del círculo indica que la necrópolis de base nunca contó con una distribución continua de tumbas sobre el terreno, y que su concentración en el interior de recintos bien limitados constituye un rasgo característico de la necrópolis desde sus primeros momentos. La distribución espacial de las tumbas con urnas bicónicas en la necrópolis de base del túmulo A (A32, A44, A47, A48, A52,
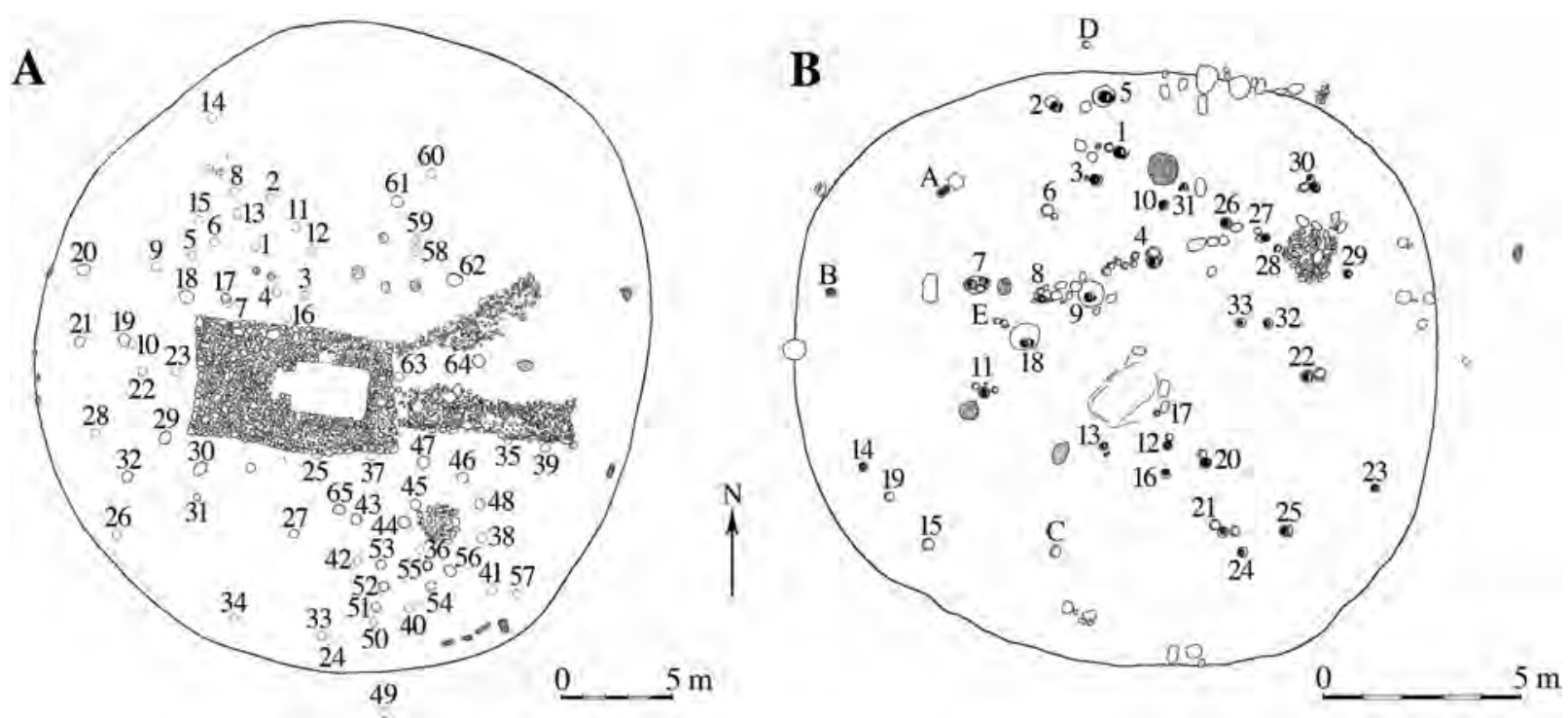

Fig. 2. Setefilla (Lora del Río, Sevilla). Planta del túmulo A: las delimitaciones en línea continua corresponden a tumbas de la necrópolis de base y en línea discontinua a tumbas en la cubierta tumular; Planta del túmulo B (según Aubet 1980-1981: figs. 1 y 2 respectivamente).

\footnotetext{
${ }^{4}$ Krueger, M. 2011: Estructura social tartésica a través del ejemplo de la necrópolis de Setefilla (Lora del Río, Sevilla). Tesis doctoral inédita, Universitat Pompeu Fabra. Barcelona.
}

A56) incluso parece indicar que pudiera haber existido un núcleo original de sepulturas concentradas alrededor de un amontonamiento de piedras 
situado en el cuadrante suroriental del respectivo círculo funerario (Fig. 2A). Sin embargo no nos atrevemos a defender la existencia de una "fase 0" (¿pre-círculo funerario?) sólo a partir de este hecho.

En la fase II solo se edificó la cámara central. Posiblemente fue expoliada ya en la Antigüedad o durante la Edad Media, puesto que se encontraron en su interior fragmentos de cerámica medieval. Después se intervino en 1902 por lo que apareció vacía durante las excavaciones de Bonsor y Thouvenot (1928: 12-14) en los años veinte. Lo relevante para nuestro estudio son las implicaciones que tuvo la edificación del monumento para la estructura del túmulo A y el motivo de su construcción. La cámara supuso la destrucción de las tumbas que estaban dispersas en el centro del túmulo como atestiguan A25 y A63, que aparecieron afectadas justo por debajo de la cámara. Puede haber más tumbas bajo los muros de la cámara, puesto que esta no ha sido derrumbada durante las excavaciones. No hay posibilidad de encontrar otros restos arqueológicos en la cámara. Como el suelo está a $80 \mathrm{~cm}$ por debajo del estrato correspondiente a la necrópolis, si hubiera habido tumbas in situ, habrían sido extraídas durante el proceso de la excavación del interior. De todos modos, puede que algunas urnas registradas por Aubet al nivel del terreno natural en el exterior de la cámara corresponden a tumbas exhumadas en la excavación de su recinto interior y redepositadas antes de la edificación del propio túmulo (véase abajo).

La fase III se caracteriza sobre todo por la construcción de dos muros adosados a la cámara: uno, de considerable grosor, tapa la entrada y otro refuerza la pared oriental. En el mismo momento se depositaron cuatro urnas (A12 a A14, A24) por encima del estrato de la necrópolis de base. No se han detectado cambios estilísticos en sus ajuares. Es posible que se trate de urnas exhumadas en la excavación del interior de la cámara durante la fase II, y redepositadas al exterior de la cámara con más cuidado que él reservado al contenido de las tumbas destruidas en las remociones de tierra que debieron tener lugar durante la construcción del propio túmulo. La determinación radiocarbónica obtenida a partir del material óseo procedente de la urna A13 con alguna probabilidad es más antigua que la mayoría de las tumbas de la necrópolis de base. Por ello, esta segunda posibili- dad quizás resulta más verosímil que el escenario propuesto en su momento por Aubet (1975: 72). Discutiremos más abajo las posibles razones para un tratamiento diferente de las tumbas exhumadas en la excavación del interior de la cámara frente a las destruidas en las remociones de tierra posteriores. Este escenario, de todos modos, significaría que no hay ningún desfase temporal entre la fase III y la fase II.

La fase IV está relacionada con la construcción de la gran cubierta tumular. De la fase IV se conocen 20 urnas procedentes de las tumbas A1 a A11, A35 a A40 y A58 a A60. La presencia de las urnas con sus respectivos ajuares y restos óseos es una de las cuestiones más interesantes de la necrópolis de Setefilla. Se trata de un material revuelto y destruido, a primera vista, sin indicios de haber sido tratado con respeto.

\section{LAS ESTRUCTURAS FUNERARIAS DEL TÚMULO B}

El túmulo $\mathrm{B}$ se diferencia del túmulo $\mathrm{A}$ por sus menores dimensiones $(17 \mathrm{~m} \times 15 \mathrm{~m})$ y por la bastante clara situación estratigráfica de las 33 tumbas que Aubet (1978) registró durante sus excavaciones.

De la fase 1, correspondiente a la necrópolis de base, se conocen hasta 31 urnas funerarias provenientes de 30 tumbas (la tumba 12 tiene dos urnas). La tumba descubierta por Bonsor en el túmulo $\mathrm{B}$ se corresponde con la tumba 17 por lo que, en este caso, se debe considerar el vaso à chardon como urna (Fig. 2B).

Aubet (1978: 167) menciona sólo 3 tumbas (B10, B20, B21) de la fase II, localizadas en el estrato III del túmulo, por lo que deberían ser posteriores a todas las tumbas de la necrópolis de base. De cualquier forma, la documentación estratigráfica disponible no permite descartar con certeza absoluta que algunas de las 31 tumbas asignadas a la necrópolis de base pertenecieran a esta fase más reciente.

Del relleno tumular procede una considerable cantidad de cerámicas, bronces y huesos calcinados. Ello puede significar que se utilizaron tierras procedentes de otro sector de la necrópolis de base en la construcción del túmulo (Aubet 1978: 166). 


\section{INTRODUCCIÓN A LAS CUESTIONES CRONOLÓGICAS}

La cronología del Bronce Final y Hierro Antiguo en el valle del Guadalquivir provoca largas disputas. El debate concierne al comienzo de la llamada cultura tartésica y a la cronología de sus yacimientos principales, entre los que se encuentra la necrópolis de Setefilla.

Hace casi treinta años, cuando no había dataciones precisas de otros sitios arqueológicos y el conocimiento del periodo orientalizante era incomparablemente peor que hoy en día, se pensaba que la cronología de los túmulos $\mathrm{A}$ y $\mathrm{B}$ de Setefilla oscilaba entre el siglo VII y el VI a.C. (Aubet 1975: 153, 1978: 222). Esta asignación ha sido revisada tanto por la propia directora de las excavaciones en Setefilla (Aubet et al. 1996: 146), como por otros investigadores (Torres 1996: 158; Beba 2008: 132-133). En la actualidad, se percibe la necrópolis de Setefilla, entendida como un lugar de enterramiento sin diferenciar las entidades concretas, como una fundación del Bronce Final, o incluso anterior (Aubet 1997: 170). Tanto en el túmulo $\mathrm{A}$ como en el túmulo $\mathrm{B}$ hay tumbas con ítems pertenecientes a la cultura material del Bronce Final. Además esos enterramientos no contienen artefactos de tradición fenicia, ni otros objetos típicos de la Edad del Hierro, como por ejemplo cuchillos afalcatados.

Lo que presenta una enorme dificultad es la situación cronológica del túmulo B. Desde la publicación de la memoria de la excavación (Aubet 1978) se ha considerado algo posterior al túmulo A. El argumento más consistente para defenderlo es la morfología de los cuencos en los que desaparece progresivamente la carena (Aubet 1978: 222). Este hecho está confirmado, en efecto, por la secuencia estratigráfica de los estratos VII-VI del Corte 1 (Aubet 1989: 302, fig. 17 y 18) y el estrato VII del Corte 3 (Aubet et al. 1983: 97-100) de la Mesa de Setefilla. Sin embargo, como veremos más adelante, esta supuesta secuencia en la ocupación funeraria de los dos túmulos no encaja muy bien con los resultados de nuestro programa de determinaciones radiocarbónicas.

De cualquier modo, se infiere de las memorias de excavación de la necrópolis de Setefilla (Aubet 1975,1978 ) que los materiales del túmulo A y túmulo B, aunque muy parecidos, presentan ciertas diferencias. La más importante es que el perfil de los cuencos corresponde a estratos distintos en la Mesa de Setefilla ${ }^{5}$. Resulta difícil basar la cronología absoluta en exclusiva en las semejanzas o diferencias entre materiales, puesto que los yacimientos que sirven como puntos de referencia tampoco tienen unas secuencias cronológicas del todo fiables. La solución sólo puede consistir en utilizar métodos de datación absoluta, a pesar de los problemas que, por la forma de la curva de calibración, sufren las determinaciones radiocarbónicas en el intervalo temporal entre 760 y $400 \mathrm{cal} \mathrm{AC.}$

En su momento en Setefilla se hicieron cuatro determinaciones radiocarbónicas sobre carbón vegetal, procedentes de los estratos IX a XIV del Corte 3 del poblado (Aubet et al. 1983: 48-49), pero, hasta que emprendimos nuestro programa de investigación no se disponía de dataciones absolutas relacionadas con la necrópolis. Este vacío se debe principalmente a las dificultades persistentes para obtener determinaciones radiocarbónicas fiables sobre hueso cremado. Esta situación empezó a cambiar tan sólo a partir de inicios de los años 2000, pero todavía se corresponde con una escasa representación de contextos fechados del Bronce Final y de inicios de la Edad del Hierro entre las determinaciones disponibles para el Sudoeste de la Península Ibérica en general (García y Odriozola 2012).

\section{EL NUEVO PROGRAMA DE DETERMINACIONES RADIOCARBÓNICAS}

Los avances logrados durante los últimos 20 años en la aplicación de la analítica radiocarbónica a la materia ósea cremada han hecho posible el programa de determinaciones radiocarbónicas sobre restos humanos de la necrópolis de Setefilla, cuyos resultados se presentan en estas páginas. Dicho método se diferencia de otros enfoques analíticos en varios aspectos importantes. En los huesos no alterados por el proceso de cremación se aprovecha el colágeno que forma la parte orgánica del tejido óseo para efectuar las determinaciones radiocarbónicas. En cambio, en los restos óseos cremados se

\footnotetext{
${ }^{5}$ Consúltese el cuadro de correlaciones de los sectores excavados en Setefilla (Aubet et al. 1983: fig. 63) y compárense los materiales procedentes de los estratos XI-VIII con los de los estratos VII-VI del Corte 1 y 3 de la Mesa de Setefilla.
} 
utiliza la bioapatita, un fosfato de calcio que constituye el componente principal de la parte mineralizada de la matriz ósea, debido a la descomposición química que sufre el colágeno una vez expuesto a una temperatura superior a $500-600^{\circ} \mathrm{C}$.

La dificultad del método consiste en que la bioapatita queda fácilmente contaminada por carbonatos procedentes del medio pedológico. Por ello, durante mucho tiempo se ha considerado inadecuado para obtener dataciones radiocarbónicas fiables. Eso solo empezó a cambiar a finales de los años noventa cuando un equipo del laboratorio de radiocarbono de la Universidad de Groninga consiguió demonstrar que la recristalización que sufre la bioapatita a partir de una temperatura de $600-700^{\circ} \mathrm{C}$ puede eliminar el riesgo de este tipo de contaminación postdeposicional (Lanting y Brindley 1999; Lanting et al. 2001). El método sigue contando con una serie de limitaciones, pero su fiabilidad fundamental enseguida fue verificada también por otros laboratorios y hoy en día está fuera de duda (Naysmith et al. 2007). Los protocolos de laboratorio empleados en el marco de nuestro programa de determinaciones radiocarbónicas se detallan en Reimer et al. (2015).

El programa que presentamos en este trabajo constituye el primer intento de aplicar este método de una manera sistemática y extensiva al mundo funerario del Bronce Final y Hierro Antiguo en el ámbito geográfico del Sudoeste peninsular. Hasta el momento, solo se disponía de dos dataciones sobre biopatita procedentes de la necrópolis de Medellín (Almagro Gorbea et al. 2008: 875).

\section{Estrategia y problemas del muestreo}

La decisión de centrar nuestro programa de investigación en la necrópolis de Setefilla se debe a la riqueza de su registro y a su posición cronológica en la transición Bronce Final/Hierro Antiguo. En un principio se buscaba un muestreo completo, o sea, obtener una determinación radiocarbónica para cada una de las tumbas de incineración documentadas en la excavación de los túmulos A y $\mathrm{B}$ con material de muestra adecuado. El objetivo principal de esta estrategia era superar algunos de los problemas provocados por el tramo relativamente llano que caracteriza la curva de calibración entre 760 y 400 cal AC, la llamada "meseta de Hallstatt" o anomalía de Vries IIIb (Taylor et al. 1996: 663 fig. 3A). Esta meseta resulta en una falta de precisión en las dataciones calibradas que caen en este intervalo, y limita severamente la resolución cronológica que se puede lograr para el período correspondiente (Fig. 3).

De todas formas, la meseta de Hallstatt no es completamente llana. En concreto entre 760 y 650 cal AC luce algunas oscilaciones que, en principio, dado un número suficiente de dataciones de alta precisión, ancladas en datos estratigráficos o en una seriación estadística de ajuares, se pueden aprovechar para superar - hasta cierto punto- los

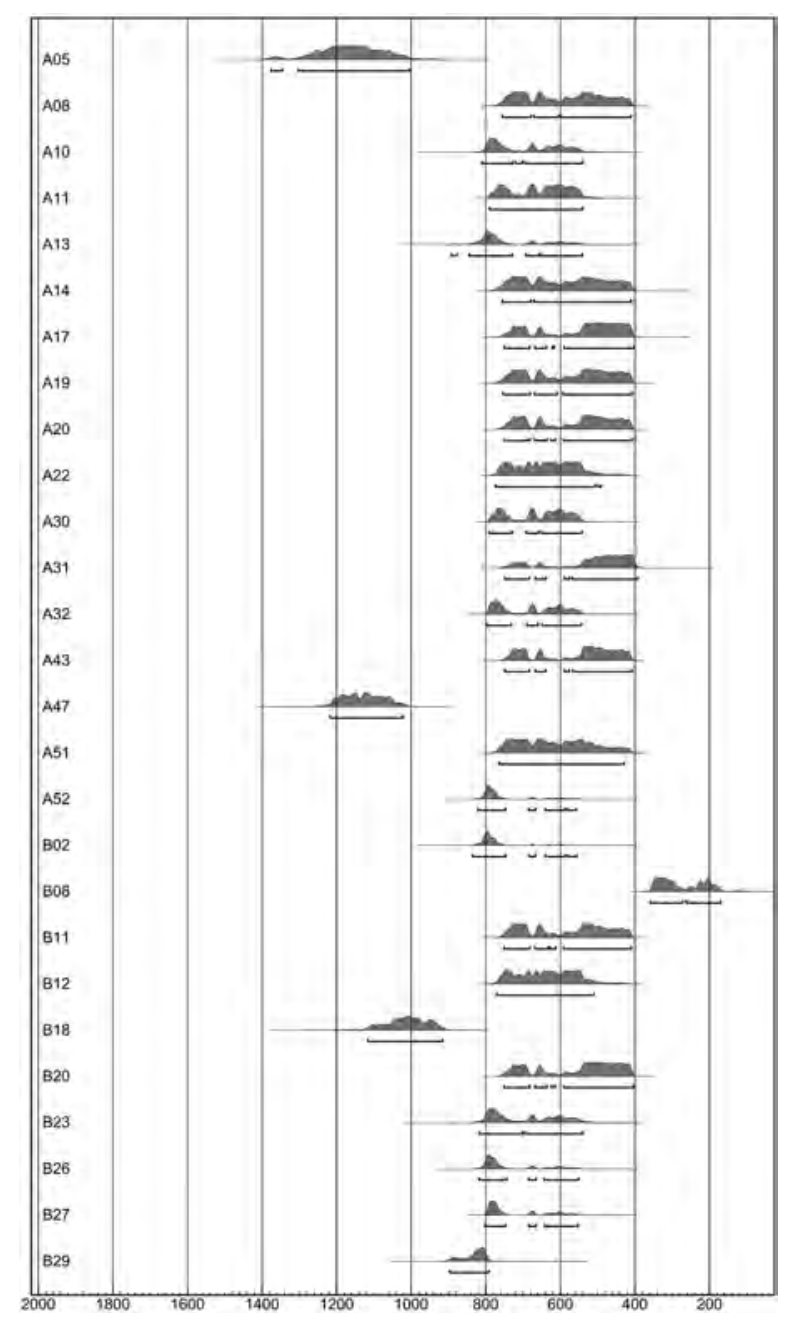

Fig. 3. Gráfico de las determinaciones radiocarbónicas calibradas (cal AC) de los túmulos A y B de Setefilla listadas en la tabla 2 (programa OxCal 4.2.4 [Bronk Ramsey 2013] sobre la curva de calibración IntCal13 [Reimer et al. 2013]). 
efectos negativos de la meseta de Hallstatt (Manning y Weninger 1992: 638-647; Christen y Litton 1995: 721-723). Al final, en nuestro caso no logramos poner en práctica este método porque la mayoría de los resultados del análisis radiocarbónico carecían de los requisitos necesarios respecto al número de determinaciones fiables, a su incertidumbre de medición y a la posibilidad de establecer la posición de los respectivos ajuares en una secuencia relativa. Dos factores principales limitaron la disponibilidad de material de muestra de las 99 tumbas en cuestión, reduciendo a 27 las que se podían incluir en el programa,

El primero fue que no todas las tumbas contaban con una cuantidad de materia ósea suficiente. En las excavaciones de los años setenta no se registraron restos óseos en 12 de las tumbas del túmulo $\mathrm{A}$, sin contar la cámara principal violada, mientras que en el túmulo $\mathrm{B}$ un par de tumbas no contenían material óseo. Aparte de estos aparentes cenotafios, en varias tumbas más se registró una cantidad muy escasa de huesos. Según la documentación disponible, en ninguna tumba se encontraron los restos completos del individuo. Claramente en los túmulos A y B de Setefilla los huesos depositados en urna representan tan sólo una pequeña muestra del esqueleto cremado. Este fenómeno de enterramientos simbólicos también se ha observado en otras necrópolis de incineración coetáneas (Kalb y Höck 1980: 101-104; Vilaça et al. 1999: 13, 29), pero aun así resultaba más pronunciado de lo que inicialmente se había esperado en el marco de nuestro proyecto. En consecuencia, a veces simplemente no se contaba con materia ósea suficiente para emprender una determinación radiocarbónica. Por motivos de conservación tampoco se incluyeron en el muestreo las tumbas donde la mínima cantidad de hueso disponible hubiera significado su consumo total en el proceso de analítica.

Otro factor limitador del número de determinaciones radiocarbónicas viables era la calcinación incompleta de buena parte del material óseo disponible. Sólo un hueso suficientemente calcinado, donde la bioapatita ha experimentado una recristalización completa permite evitar el peligro de contaminación postdeposicional por carbonatos exógenos. Por lo tanto, ya en una primera revisión de materiales en el Museo Arqueológico de Sevilla, se preseleccionaron las muestras según aspectos visuales indicativos del grado de calcina- ción. Si era posible, se intentó recoger fragmentos óseos de colores claros, es decir, cremados a temperaturas altas (Trellisó 2001: 91; Ellingham et al. 2015: 182-184). De esta manera se llegó a obtener muestras de 65 de las 99 tumbas documentadas en los túmulos A y $\mathrm{B}$, incluyendo una muestra sobre hueso de animal no cremado.

En un segundo paso, todas las muestras sobre hueso cremado preseleccionadas se analizaron por espectroscopia infrarroja con transformada de Fourier (FTIR) para determinar su índice de cristalinidad (IC). Los resultados fueron bastante variables, con valores IC entre 2,8 y 6,3 . Como los valores IC en materia ósea completamente recristalizada suelen caer entre 5,0 y 7,0, para evitar cualquier riesgo de contaminación postdeposicional por absorción de carbonatos exógenos, se estableció un valor umbral de 5,0 (Thompson et al. 2009; Thompson et al. 2011). Muestras con un valor IC bajo este umbral se excluyeron del programa, lo que ocasionó la invalidación de la mayoría de las muestras preseleccionadas. A veces se disponía de suficiente material óseo para conseguir otra muestra de una misma sepultura, sustituyendo así alguna de las muestras descartadas. Sin embargo, del total de 64 muestras iniciales sobre materia ósea cremada, tras la determinación del índice de cristalización, sólo se consideraron viables 26. Las restantes 38 muestras se eliminaron del programa. A estas 26 muestras sobre bioapatita se añade una muestra sobre colágeno, obtenida de un hueso de animal no cremado que formaba parte del ajuar de la tumba A11. Con ello se disponía de un total de 27 muestras consideradas aptas para conseguir determinaciones radiocarbónicas fiables (Tab. 1).

La eliminación de la mayoría de las muestras disponibles era la única manera de no perjudicar el fin último del programa: conseguir una serie de determinaciones radiocarbónicas de máxima fiabilidad para la necrópolis de Setefilla ${ }^{6}$. Las muestras

\footnotetext{
${ }^{6} \mathrm{La}$ falta de protocolos rigurosos en la selección de muestras probablemente sea la responsable de las dataciones anómalas obtenidas sobre hueso cremado en distintos proyectos anteriores. Eso atañe, por ejemplo, a las determinaciones radiocarbónicas de la necrópolis de Sebes, que no incluyen informaciones sobre el valor IC de las muestras, y donde el material muestreado se describe tanto como hueso quemado como hueso cremado (Belarte et al. 2013: 308). Hay que hacer hincapié en que el terminó "cremado" se debe reservar estrictamente para referirse a la materia ósea calcinada, mientras [sigue en p. 304]
} 


\begin{tabular}{|c|c|c|c|c|c|c|c|c|}
\hline $\begin{array}{c}\text { Código } \\
\text { laboratorio }\end{array}$ & Tipo muestra & Peso muestra & Núm. sepultura & Valor IC & $\underset{{ }^{14} \mathrm{C}}{\text { Fecha }}$ & \pm & $\mathrm{F}^{14} \mathrm{C}$ & \pm \\
\hline UB-27565 & hueso cremado & 4 & $\mathrm{~A} 01$ & 4,0 & - & - & - & - \\
\hline UB-27566 & hueso cremado & 3 & A02 & 4,0 & - & - & - & - \\
\hline UBA-27567 & hueso cremado & 3 & A05 & 5,9 & 2953 & 55 & 0,6924 & 0,0047 \\
\hline UB-27568 & hueso cremado & 3 & A06 & 4,9 & - & - & - & - \\
\hline UBA-27569 & hueso cremado & 3 & A08 & 6,1 & 2452 & 33 & 0,7369 & 0,0030 \\
\hline UB-29073 & hueso cremado & 3 & A09 & 4,6 & - & - & - & - \\
\hline UBA-27570 & hueso cremado & 3 & A10 & 5,5 & 2557 & 45 & 0,7273 & 0,0040 \\
\hline UBA-27571 & hueso de animal & 1 & A11 & $\mathrm{n} / \mathrm{a}$ & 2509 & 31 & 0,7318 & 0,0028 \\
\hline UB-27572 & hueso cremado & 4 & A12 & 4,6 & - & - & - & - \\
\hline UBA-27573 & hueso cremado & 3 & A13 & 5,5 & 2592 & 50 & 0,7242 & 0,0044 \\
\hline UBA-27574 & hueso cremado & 6 & A14 & 5,6 & 2451 & 39 & 0,7370 & 0,0035 \\
\hline UB-27575 & hueso cremado & 5 & A15 & 4,2 & - & - & - & - \\
\hline UBA-27576 & hueso cremado & 4 & A17 & 5,2 & 2427 & 33 & 0,7392 & 0,0030 \\
\hline UBA-27577 & hueso cremado & 6 & A19 & 5,9 & 2442 & 35 & 0,7379 & 0,0032 \\
\hline UBA-27578 & hueso cremado & 6 & $\mathrm{~A} 20$ & 5,2 & 2441 & 29 & 0,7380 & 0,0027 \\
\hline UB-27579 & hueso cremado & 5 & $\mathrm{~A} 21$ & 3,9 & - & - & - & - \\
\hline UBA-27580 & hueso cremado & 6 & A22 & 5,5 & 2484 & 28 & 0,7340 & 0,0026 \\
\hline UB-27581 & hueso cremado & 2 & A26 & 4,8 & - & - & - & - \\
\hline UB-27582 & hueso cremado & 4 & A29 & 4,7 & - & - & - & - \\
\hline UBA-27583 & hueso cremado & 4 & A30 & 5,4 & 2517 & 27 & 0,7310 & 0,0025 \\
\hline UBA-27584 & hueso cremado & 8 & A31 & 5,3 & 2396 & 42 & 0,7421 & 0,0039 \\
\hline UBA-27585 & hueso cremado & 4 & A32 & 6,3 & 2535 & 31 & 0,7294 & 0,0028 \\
\hline UBA-27586 & hueso cremado & 14 & A43 & 6,1 & 2438 & 24 & 0,7382 & 0,0022 \\
\hline UB-27587 & hueso cremado & 6 & A45 & 4,9 & - & - & - & - \\
\hline UB-27588 & hueso cremado & 6 & A46 & 4,4 & - & - & - & - \\
\hline UBA-27589 & hueso cremado & 2 & A47 & 5,4 & 2928 & 31 & 0,6946 & 0,0027 \\
\hline UBA-27590 & hueso cremado & 10 & A51 & 5,8 & 2466 & 33 & 0,7356 & 0,0030 \\
\hline UBA-27591 & hueso cremado & 3 & A52 & 5,6 & 2584 & 35 & 0,7250 & 0,0031 \\
\hline UB-29074 & hueso cremado & 5 & A53 & 4,5 & - & - & - & - \\
\hline UB-27592 & hueso cremado & 6 & A54 & 4,0 & - & - & - & - \\
\hline UB-27593 & hueso cremado & 3 & A55 & 4,9 & - & - & - & - \\
\hline UB-27594 & hueso cremado & 5 & A57 & 4,5 & - & - & - & - \\
\hline UB-27595 & hueso cremado & 4 & A61 & 4,3 & - & - & - & - \\
\hline UB-29075 & hueso cremado & 4 & A61 & 4,2 & - & - & - & - \\
\hline UB-27596 & hueso cremado & 8 & A62 & 4,9 & - & - & - & - \\
\hline UB-27597 & hueso cremado & 7 & A65 & 4,7 & - & - & - & - \\
\hline UB-27598 & hueso cremado & 6 & B01 & 3,8 & - & - & - & - \\
\hline UBA-27599 & hueso cremado & 8 & $\mathrm{~B} 02$ & 5,8 & 2597 & 39 & 0,7237 & 0,0035 \\
\hline UB-27600 & hueso cremado & 3 & B04 & 4,5 & - & - & - & - \\
\hline
\end{tabular}

Trab. Prehist., 74, N. ${ }^{\circ}$ 2, julio-diciembre 2017, pp. 296-318, ISSN: 0082-5638 doi: $10.3989 /$ tp.2017.12196 


\begin{tabular}{|c|c|c|c|c|c|c|c|c|}
\hline $\begin{array}{c}\text { Código } \\
\text { laboratorio }\end{array}$ & Tipo muestra & $\begin{array}{c}\text { Peso muestra } \\
(\mathrm{g})\end{array}$ & Núm. sepultura & Valor IC & $\begin{array}{c}\text { Fecha } \\
{ }^{14} \mathrm{C}\end{array}$ & \pm & $\mathrm{F}^{14} \mathrm{C}$ & \pm \\
\hline UB-27601 & hueso cremado & 6 & B05 & 4,5 & - & - & - & - \\
\hline UB-27602 & hueso cremado & 5 & B06 & 4,1 & - & - & - & - \\
\hline UB-27603 & hueso cremado & 8 & B07 & 3,6 & - & - & - & - \\
\hline UBA-27604 & hueso cremado & 5 & B08 & 5,3 & 2180 & 27 & 0,7623 & 0,0026 \\
\hline UB-27605 & hueso cremado & 8 & B09 & 4,1 & - & - & - & - \\
\hline UB-27606 & hueso cremado & 5 & $\mathrm{~B} 10$ & 4,5 & - & - & - & - \\
\hline UBA-29076 & hueso cremado & 4 & B11 & 5,1 & 2446 & 28 & 0,7375 & 0,0025 \\
\hline UBA-27607 & hueso cremado & 7 & B12 & 5,1 & 2481 & 25 & 0,7342 & 0,0023 \\
\hline UB-27608 & hueso cremado & 5 & B13 & 3,4 & - & - & - & - \\
\hline UB-27609 & hueso cremado & 4 & B14 & 4,6 & - & - & - & - \\
\hline UB-27610 & hueso cremado & 6 & $\mathrm{~B} 15$ & 4,3 & - & - & - & - \\
\hline UB-27611 & hueso cremado & 14 & B16 & 2,9 & - & - & - & - \\
\hline UBA-27612 & hueso cremado & 7 & B18 & 5,5 & 2848 & 36 & 0,7015 & 0,0031 \\
\hline UBA-29077 & hueso cremado & 8 & $\mathrm{~B} 20$ & 5,0 & 2431 & 33 & 0,7389 & 0,0030 \\
\hline UB-27613 & hueso cremado & 6 & B21 & 2,8 & - & - & - & - \\
\hline UB-27614 & hueso cremado & 3 & $\mathrm{~B} 22$ & 3,7 & - & - & - & - \\
\hline UBA-27615 & hueso cremado & 8 & B23 & 5,0 & 2564 & 49 & 0,7267 & 0,0044 \\
\hline UB-29078 & hueso cremado & 4 & B24 & 4,6 & - & - & - & - \\
\hline UB-27616 & hueso cremado & 10 & $\mathrm{~B} 25$ & 3,6 & - & - & - & - \\
\hline UBA-27617 & hueso cremado & 6 & B26 & 5,7 & 2579 & 38 & 0,7254 & 0,0034 \\
\hline UBA-27618 & hueso cremado & 2 & $\mathrm{~B} 27$ & 5,2 & 2555 & 28 & 0,7276 & 0,0025 \\
\hline UB-27619 & hueso cremado & 9 & B28 & 3,4 & - & - & - & - \\
\hline UBA-27620 & hueso cremado & 5 & B29 & 5,1 & 2658 & 38 & 0,7183 & 0,0034 \\
\hline UB-27621 & hueso cremado & 4 & $\mathrm{~B} 30$ & 2,5 & - & - & - & - \\
\hline UB-27622 & hueso cremado & 5 & B31 & 3,7 & - & - & - & - \\
\hline UB-27623 & hueso cremado & 6 & B33 & 3,1 & - & - & - & - \\
\hline
\end{tabular}

Tab. 1. Listado de las muestras procedentes de las sepulturas de los túmulos A y B de Setefilla (Lora del Río, Sevilla) en el marco del proyecto "Los inicios de la Edad del Hierro en el Sudoeste de la Península Ibérica: cronología e cultura material".

eliminadas debido a su bajo valor IC todavía apor$\tan$ datos interesantes. El hecho de que tan sólo se depositara en la mayoría de las urnas una cantidad muy reducida de huesos plantea toda una serie de

[viene de p. 302] "quemado" se refiere al material óseo no calcinado, y por lo tanto inadecuado para conseguir determinaciones radiocarbónicas fiables (Lanting y Brindley 1999: 138). Para una discusión sinóptica de los problemas metodológicos relacionados con la datación radiocarbónica de materia ósea cremada véase Brandherm et al. 2017. preguntas sobre las condiciones en que se realizaron las incineraciones y sobre los criterios de selección de los restos a depositar. Este tema, sin embargo, no constituye el foco del presente estudio.

Para compensar el alto número de conjuntos eliminados de los túmulos A y $\mathrm{B}$ de Setefilla, también se presenta en estas páginas una tumba de incineración de Monte de São Domingos (Malpica do Tejo, Castelo Branco) y otra de Rabadanes (Las Cabezas de San Juan, Sevilla), que forman parte de las incluidas en nuestro programa de in- 
vestigación. Las muestras óseas se seleccionaron según los mismos criterios que las de la necrópolis de Setefilla (Cardoso et al. 1998: 342; Pellicer y Escacena 2007: 11-12). La procedente de la tumba 1 de Rabadanes salió con un IC de 4,9 y es la única muestra en nuestro programa cuyo valor IC es inferior al del umbral de 5,0. Como no se conserva material óseo de los demás conjuntos de la necrópolis de Rabadanes, había que elegir entre una datación cuya fiabilidad estaba mínimamente reducida o que el yacimiento careciera por completo de datación. La muestra de la estructura 2 de Monte de São Domingos dio un valor IC de 5,2 (Brandherm et al. 2017: 525).

\section{Los resultados de la analítica}

La gran mayoría de las nuevas determinaciones radiocarbónicas para las tumbas de Setefilla responde a las expectativas convencionales para contextos atribuibles a la transición Bronce Final/ Hierro Antiguo y al período orientalizante del Sudoeste peninsular, cubriendo sobre todo los siglos VIII y VII cal AC. Solo algunos de los resultados caen fuera de este intervalo previsto (Tab. 2), algo que no es atribuible a posibles contaminaciones ya que se tomaron las máximas precauciones para evitarlas durante todo el proceso del muestreo.

\begin{tabular}{|c|c|c|c|c|c|c|c|}
\hline $\begin{array}{c}\text { Código } \\
\text { laboratorio }\end{array}$ & $\begin{array}{l}\text { Núm. } \\
\text { sepultura }\end{array}$ & $\begin{array}{c}\text { Fecha } \\
{ }^{14} \mathrm{C}\end{array}$ & \pm & $\begin{array}{c}\text { Fecha cal AC } \\
\text { intervalos } 1 \sigma\end{array}$ & Área relativa & $\begin{array}{c}\text { Fecha cal AC } \\
\text { intervalos } 2 \sigma\end{array}$ & Área relativa \\
\hline UBA-27567 & $\mathrm{A} 05$ & 2953 & 55 & $\begin{array}{l}1257-1247 \\
1233-1081 \\
1077-1076 \\
1064-1058 \\
\end{array}$ & $\begin{array}{l}0,045930 \\
0,913963 \\
0,008812 \\
0,031295 \\
\end{array}$ & $\begin{array}{l}1377-1347 \\
1303-1004\end{array}$ & $\begin{array}{l}0,027108 \\
0,972892\end{array}$ \\
\hline UBA-27569 & A08 & 2452 & 33 & $\begin{array}{l}748-685 \\
667-641 \\
587-580 \\
559-476 \\
461-456 \\
444-431 \\
\end{array}$ & $\begin{array}{l}0,352457 \\
0,135589 \\
0,030385 \\
0,408564 \\
0,018447 \\
0,054558 \\
\end{array}$ & $\begin{array}{l}755-680 \\
670-607 \\
596-412\end{array}$ & $\begin{array}{l}0,277002 \\
0,176286 \\
0,546712\end{array}$ \\
\hline UBA-27570 & $\mathrm{A} 10$ & 2557 & 45 & $\begin{array}{l}802-750 \\
683-668 \\
638-590 \\
576-571\end{array}$ & $\begin{array}{l}0,561666 \\
0,113483 \\
0,293982 \\
0,030869\end{array}$ & $\begin{array}{l}810-727 \\
719-704 \\
695-541\end{array}$ & $\begin{array}{l}0,466953 \\
0,013862 \\
0,519185\end{array}$ \\
\hline UBA-27571 & A11 & 2509 & 31 & $\begin{array}{l}771-746 \\
686-666 \\
643-554\end{array}$ & $\begin{array}{l}0,192333 \\
0,156470 \\
0,651197\end{array}$ & $\begin{array}{l}789-701 \\
696-540\end{array}$ & $\begin{array}{l}0,290661 \\
0,709339\end{array}$ \\
\hline UBA-27573 & A13 & 2592 & 50 & $\begin{array}{l}825-753 \\
681-669 \\
610-594\end{array}$ & $\begin{array}{l}0,858385 \\
0,061808 \\
0,079807\end{array}$ & $\begin{array}{l}891-879 \\
844-729 \\
693-658 \\
653-542\end{array}$ & $\begin{array}{l}0,007719 \\
0,676557 \\
0,076311 \\
0,239413\end{array}$ \\
\hline UBA-27574 & A14 & 2451 & 39 & $\begin{array}{l}747-685 \\
666-641 \\
587-581 \\
556-471 \\
466-451 \\
446-430 \\
\end{array}$ & $\begin{array}{l}0,330212 \\
0,124821 \\
0,019610 \\
0,404797 \\
0,055074 \\
0,065486 \\
\end{array}$ & $\begin{array}{l}756-679 \\
671-604 \\
599-411\end{array}$ & $\begin{array}{l}0,262394 \\
0,180912 \\
0,556693\end{array}$ \\
\hline UBA-27576 & A17 & 2427 & 33 & $\begin{array}{l}727-719 \\
704-695 \\
541-411\end{array}$ & $\begin{array}{l}0,043991 \\
0,055455 \\
0,900555\end{array}$ & $\begin{array}{l}750-683 \\
668-638 \\
621-619 \\
591-404\end{array}$ & $\begin{array}{l}0,198385 \\
0,068419 \\
0,002708 \\
0,730489\end{array}$ \\
\hline UBA-27577 & A19 & 2442 & 35 & $\begin{array}{l}734-689 \\
662-648 \\
546-427 \\
422-416 \\
\end{array}$ & $\begin{array}{l}0,259301 \\
0,074268 \\
0,634298 \\
0,032133 \\
\end{array}$ & $\begin{array}{l}753-681 \\
669-610 \\
594-408\end{array}$ & $\begin{array}{l}753-681 \\
669-610 \\
594-408\end{array}$ \\
\hline UBA-27578 & $\mathrm{A} 20$ & 2441 & 29 & $\begin{array}{l}732-690 \\
661-650 \\
545-451 \\
449-430\end{array}$ & $\begin{array}{c}0,262238 \\
0,064561 \\
0,566102 \\
0,107099\end{array}$ & $\begin{array}{l}751-682 \\
668-636 \\
626-614 \\
592-408\end{array}$ & $\begin{array}{l}0,251599 \\
0,093022 \\
0,015120 \\
0,640259\end{array}$ \\
\hline
\end{tabular}

Trab. Prehist., 74, N. ${ }^{\circ}$, julio-diciembre 2017, pp. 296-318, ISSN: 0082-5638 doi: $10.3989 /$ tp. 2017.12196 


\begin{tabular}{|c|c|c|c|c|c|c|c|}
\hline $\begin{array}{c}\text { Código } \\
\text { laboratorio }\end{array}$ & $\begin{array}{c}\text { Núm. } \\
\text { sepultura }\end{array}$ & $\underset{{ }^{14} \mathrm{C}}{\text { Fecha }}$ & \pm & $\begin{array}{c}\text { Fecha cal AC } \\
\text { intervalos } 1 \sigma\end{array}$ & Área relativa & $\begin{array}{l}\text { Fecha cal AC } \\
\text { intervalos } 2 \sigma \\
\end{array}$ & Área relativa \\
\hline UBA-27580 & A22 & 2484 & 28 & $\begin{array}{l}757-730 \\
691-678 \\
672-659 \\
651-544 \\
\end{array}$ & $\begin{array}{l}0,169027 \\
0,080663 \\
0,075059 \\
0,675252 \\
\end{array}$ & $\begin{array}{l}774-508 \\
499-491\end{array}$ & $\begin{array}{l}0,994262 \\
0,005738\end{array}$ \\
\hline UBA-27583 & A30 & 2517 & 27 & $\begin{array}{l}776-748 \\
684-667 \\
640-588 \\
579-561\end{array}$ & $\begin{array}{l}0,254835 \\
0,166191 \\
0,445456 \\
0,133518\end{array}$ & $\begin{array}{l}792-729 \\
693-658 \\
653-542\end{array}$ & $\begin{array}{l}0,294467 \\
0,161322 \\
0,544211\end{array}$ \\
\hline UBA-27584 & A31 & 2396 & 42 & $\begin{array}{l}536-527 \\
521-402\end{array}$ & $\begin{array}{l}0,047181 \\
0,952819\end{array}$ & $\begin{array}{l}749-684 \\
667-639 \\
589-577 \\
567-392 \\
\end{array}$ & $\begin{array}{l}0,136900 \\
0,043543 \\
0,008557 \\
0,811000 \\
\end{array}$ \\
\hline UBA-27585 & A 32 & 2535 & 31 & $\begin{array}{l}793-750 \\
683-668 \\
638-590 \\
\end{array}$ & $\begin{array}{l}0,497759 \\
0,144980 \\
0,357261 \\
\end{array}$ & $\begin{array}{l}798-732 \\
690-661 \\
650-544 \\
\end{array}$ & $\begin{array}{l}0,410619 \\
0,137247 \\
0,452133\end{array}$ \\
\hline UBA-27586 & A43 & 2438 & 24 & $\begin{array}{l}729-692 \\
658-652 \\
543-471 \\
466-452 \\
446-430\end{array}$ & $\begin{array}{l}0,248471 \\
0,037685 \\
0,529542 \\
0,083462 \\
0,100839\end{array}$ & $\begin{array}{l}749-684 \\
667-639 \\
589-577 \\
568-408\end{array}$ & $\begin{array}{l}0,239688 \\
0,076796 \\
0,014020 \\
0,669496\end{array}$ \\
\hline UBA-27589 & A47 & 2928 & 31 & $\begin{array}{l}1194-1142 \\
1133-1075 \\
1065-1057\end{array}$ & $\begin{array}{l}0,455366 \\
0,491325 \\
0,053309\end{array}$ & $1217-1023$ & 1,000000 \\
\hline UBA-27590 & A51 & 2466 & 33 & $\begin{array}{l}751-682 \\
669-634 \\
628-613 \\
592-516\end{array}$ & $\begin{array}{l}0,381996 \\
0,188355 \\
0,065857 \\
0,363793\end{array}$ & $\begin{array}{l}765-471 \\
466-430\end{array}$ & $\begin{array}{l}0,944561 \\
0,055439\end{array}$ \\
\hline UBA-27591 & A52 & 2584 & 35 & $805-770$ & 1,000000 & $\begin{array}{l}820-748 \\
684-667 \\
640-588 \\
579-560\end{array}$ & $\begin{array}{l}0,846177 \\
0,040621 \\
0,091194 \\
0,022008\end{array}$ \\
\hline UBA-27599 & B02 & 2597 & 39 & $810-772$ & 1,000000 & $\begin{array}{l}835-748 \\
684-667 \\
640-588 \\
579-560\end{array}$ & $\begin{array}{l}0,880150 \\
0,031259 \\
0,071632 \\
0,016958\end{array}$ \\
\hline UBA-27604 & B08 & 2180 & 27 & $\begin{array}{l}353-293 \\
230-218 \\
214-195\end{array}$ & $\begin{array}{l}0,690218 \\
0,107735 \\
0,202047\end{array}$ & $\begin{array}{l}359-272 \\
262-171\end{array}$ & $\begin{array}{l}0,574251 \\
0,425749\end{array}$ \\
\hline UBA-29076 & B11 & 2446 & 28 & $\begin{array}{l}738-688 \\
663-646 \\
548-472 \\
465-452 \\
446-430\end{array}$ & $\begin{array}{l}0,321734 \\
0,099562 \\
0,451591 \\
0,057044 \\
0,070069\end{array}$ & $\begin{array}{l}752-682 \\
669-632 \\
630-612 \\
593-410\end{array}$ & $\begin{array}{l}0,271656 \\
0,109386 \\
0,024824 \\
0,594133\end{array}$ \\
\hline UBA-27607 & B12 & 2481 & 25 & $\begin{array}{l}755-729 \\
693-679 \\
671-658 \\
653-606 \\
597-542\end{array}$ & $\begin{array}{l}0,175459 \\
0,083244 \\
0,083302 \\
0,299527 \\
0,358469\end{array}$ & $770-512$ & 1,000000 \\
\hline UBA-27612 & B18 & 2848 & 36 & $\begin{array}{c}1053-970 \\
961-934\end{array}$ & $\begin{array}{l}0,797416 \\
0,202584\end{array}$ & 1116-916 & 1,000000 \\
\hline UBA-29077 & B20 & 2431 & 33 & $\begin{array}{l}728-716 \\
708-694 \\
657-654 \\
542-413\end{array}$ & $\begin{array}{l}0,062314 \\
0,079539 \\
0,010916 \\
0,847231\end{array}$ & $\begin{array}{l}751-683 \\
668-637 \\
623-615 \\
591-405\end{array}$ & $\begin{array}{l}0,212797 \\
0,076930 \\
0,008440 \\
0,701833\end{array}$ \\
\hline UBA-27615 & B23 & 2564 & 49 & $\begin{array}{l}805-749 \\
684-667 \\
639-589 \\
577-569\end{array}$ & $\begin{array}{l}0,573353 \\
0,106127 \\
0,281433 \\
0,039087\end{array}$ & $\begin{array}{l}817-701 \\
696-540\end{array}$ & $\begin{array}{l}0,503091 \\
0,496909\end{array}$ \\
\hline
\end{tabular}

Trab. Prehist., 74, N. ${ }^{\circ}$ 2, julio-diciembre 2017, pp. 296-318, ISSN: 0082-5638 doi: 10.3989/tp.2017.12196 


\begin{tabular}{|c|c|c|c|c|c|c|c|}
\hline $\begin{array}{c}\text { Código } \\
\text { laboratorio }\end{array}$ & $\begin{array}{c}\text { Núm. } \\
\text { sepultura }\end{array}$ & $\begin{array}{c}\text { Fecha } \\
{ }^{14} \mathrm{C}\end{array}$ & \pm & $\begin{array}{c}\text { Fecha cal AC } \\
\text { intervalos } 1 \sigma\end{array}$ & Área relativa & $\begin{array}{l}\text { Fecha cal AC } \\
\text { intervalos } 2 \sigma\end{array}$ & Área relativa \\
\hline UBA-27617 & B26 & 2579 & 38 & $\begin{array}{l}808-758 \\
678-673\end{array}$ & $\begin{array}{l}0,967888 \\
0,032112\end{array}$ & $\begin{array}{l}818-744 \\
686-665 \\
644-551 \\
\end{array}$ & $\begin{array}{l}0,739115 \\
0,062046 \\
0,198839 \\
\end{array}$ \\
\hline UBA-27618 & $\mathrm{B} 27$ & 2555 & 28 & $\begin{array}{l}798-756 \\
679-671 \\
604-599\end{array}$ & $\begin{array}{l}0,900686 \\
0,061763 \\
0,037551\end{array}$ & $\begin{array}{l}802-747 \\
685-666 \\
642-586 \\
585-555 \\
\end{array}$ & $\begin{array}{l}0,681341 \\
0,081161 \\
0,178649 \\
0,058849 \\
\end{array}$ \\
\hline UBA-27620 & B29 & 2658 & 38 & $840-797$ & 1,000000 & $896-793$ & 1,000000 \\
\hline
\end{tabular}

Tab. 2. Determinaciones radiocarbónicas obtenidas de las muestras procedentes de las sepulturas de los túmulos A y B de Setefilla con un valor IC $>5$ (calibración con el programa Calib 7.0.4 [Stuiver et al. 2014] sobre la curva de calibración IntCal13 [Reimer et al. 2013]).

La determinación radiocarbónica obtenida a partir del material óseo de la tumba B8 entre los siglos IV y II cal AC resulta rotundamente incompatible con la tipología de los dos recipientes cerámicos que constituyen su ajuar (Aubet 1978: 184, fig. 14). Como esta anomalía no es fácilmente explicable no queda más remedio que excluir este resultado atípico de las consideraciones que en estas páginas vamos desarrollando.

Por el otro lado las tres determinaciones de las tumbas A5, A47 y B18 señalan fechas bastante anteriores al siglo VIII, la cronología actualmente aceptada para el inicio de la ocupación funeraria de los túmulos A y $\mathrm{B}$ (Aubet et al. 1996: 146; Torres 1996: 147 y 158, 1999: 95). Es poco probable que estos tres resultados sean erróneos, dado que las tres tumbas se asocian a urnas bicónicas y un creciente número de análisis radiocarbónicos de otros yacimientos hacen necesario revisar la cronología convencionalmente atribuida a esta categoría de productos alfareros. Desafortunadamente, las tres tumbas no contenían más ajuar que las urnas bicónicas, cuya escasa asociación con otros materiales también se observa en otros yacimientos funerarios del Sudoeste peninsular (Murillo et al. 2005: 27-31).

La desventura que implica la meseta de Hallstatt hace difícil refinar la cronología interna de los túmulos A y B durante el respectivo intervalo de tiempo sobre la base de las determinaciones radiocarbónicas. Sin embargo, los nuevos datos permiten una serie de conclusiones tanto sobre la evolución de la necrópolis de Setefilla como sobre la cronología del Bronce Final y Hierro Antiguo del Sudoeste peninsular en general. Los respectivos argumentos se desarrollarán de una manera detallada en el siguiente apartado.

Antes de entrar en la discusión pormenorizada de los resultados de nuestro programa queda subrayar que faltan condiciones para una modelación válida de las nuevas determinaciones radiocarbónicas de Setefilla basadas en la estadística bayesiana (Bronk Ramsey 2009; Bronk Ramsey et al. 2010). Ello se debe a la naturaleza del contexto de las muestras con múltiples casos de redeposición secundaria de urnas y ajuares -no siempre muy evidentes- y la consiguiente falta de una inequívoca ordenación estratigráfica, así como a la distribución de los resultados de la analítica sobre la curva de la calibración.

\section{DISCUSIÓN}

En este apartado pretendemos discutir primero el potencial de las nuevas determinaciones radiocarbónicas para resolver cuestiones de la cronología interna de los túmulos A y B. En segundo lugar abordaremos la relación cronológica entre la necrópolis y el poblado de Setefilla, y finalmente debatiremos las repercusiones generales de las nuevas determinaciones sobre la cronología del Bronce Final y Hierro Antiguo en el Sudoeste peninsular.

En lo que atañe el periodo de uso de los dos túmulos, resulta evidente con los nuevos datos de nuestro programa de investigación que la ocupación funeraria del túmulo A en su fase I, 
la necrópolis de base, comienza ya en pleno II milenio, más concretamente en el intervalo entre 1217 y 1023 cal AC, marcado por la tumba A47. La determinación radiocarbónica de la tumba A5 posiblemente indica una fecha aún más temprana, con un intervalo entre 1377 y 1004 cal AC. Sin embargo destacamos que esta urna forma parte del conjunto de materiales redepositados durante la fase IV del monumento, correspondiendo a la construcción de la gran cubierta tumular. Sin embargo la mayor parte de las tumbas del túmulo A, tanto las de la necrópolis de base como las redepositadas en la cubierta tumular, son posteriores al final del siglo IX cal AC. Entre ellas, las determinaciones radiocarbónicas de las tumbas A13 y A52 con un cierto grado de probabilidad se colocan en un momento anterior a la "meseta de Hallstatt" en la curva de calibración, o sea, antes de mediados del siglo VIII cal AC (Tab. 2; Fig. 3), aunque no se pueden descartar por completo fechas algo más recientes. El resto de las determinaciones radiocarbónicas del túmulo A con bastante probabilidad también caen en el siglo VIII o en los inicios del siglo VII cal AC. Descartamos fechas en los siglos VI y V cal AC que son perfectamente posibles desde el punto de vista estadístico en la mayoría de los casos, pero más bien imposibles desde la perspectiva de su cultura material.

En este contexto hay que llamar la atención sobre la posición estratigráfica de la tumba A13, que permite su atribución inequívoca a la fase III del túmulo, o sea al momento de la construcción de los dos muros adosados a la cámara, inmediatamente anterior a la construcción de la gran cubierta tumular. Como indicamos más arriba, Aubet (1975: 72-73), aunque hacía hincapié en que ni el ajuar de la tumba A13, ni los de las tumbas A12, A14 y A24 halladas en la misma situación estratigráfica se distinguían de los ajuares asociadas a la necrópolis de base, suponía que la datación de estas cuatro tumbas era más reciente que la de la necrópolis de base Sin embargo, la probable atribución de la tumba A13 a un momento anterior a mediados del siglo VIII cal AC hace pensar en un eventual reentierro de estas cuatro urnas, quizás exhumadas de su posición original en el centro del círculo funerario durante la excavación del espacio interior de la cámara en la fase II. Si fuera así, implicaría una fecha muy temprana para el plato de bar- niz rojo que forma parte del ajuar de la tumba A13 (Aubet 1975: 84 fig. 19). Ello difícilmente se reconcilia con la cronología tradicionalmente atribuida al inicio de la colonización fenicia en el mediodía peninsular (debate en Torres 1998; Brandherm 2008a, 2008b; Gilboa 2013; López et al. 2016).

Aubet (1975: 72) ya dedujo la redeposición secundaria en la cubierta tumular de los conjuntos funerarios, atribuibles por su posición estratigráfica a la fase IV del monumento. Se basó en el estado volcado y disperso de las respectivas urnas y demás elementos de ajuar, tanto como en su aparente contemporaneidad -en términos de su cronología relativa- con los ajuares de la necrópolis de base. Las cuatro determinaciones radiocarbónicas ahora disponibles para este grupo de tumbas (A5, A8, A10, A11) concuerdan plenamente con esta interpretación. Ya arriba se mencionó que la determinación radiocarbónica de la tumba A5 es la más temprana de toda la necrópolis, precediendo a la mayoría de las tumbas de la necrópolis de base debajo del túmulo A. Su probable origen, como el de las demás tumbas redepositadas en la cubierta del túmulo, habrá que buscarlo entonces en otra parte de la necrópolis, destruida en la remoción de tierras ocasionada por la construcción del túmulo A.

La fecha más antigua para la ocupación funeraria del túmulo $\mathrm{B}$ se puede deducir de la determinación radiocarbónica de la tumba B18, y cae en el intervalo entre 1116 y 916 cal AC, coetáneo o ligeramente posterior a la fecha más antigua de la necrópolis de base del túmulo $\mathrm{A}$. Las demás determinaciones radiocarbónicas del túmulo $\mathrm{B}$ también indican dataciones similares a las de la mayoría del túmulo A, pero la proporción de determinaciones que con un alto grado de probabilidad preceden el inicio de la "meseta de Hallstatt" resulta bastante más elevada que en el caso anterior (B2, B23, B26, B27, B29).

La consecuencia es la dificultad de mantener la sucesión cronológica que supusieron Aubet et al. (1996: 146) entre las ocupaciones orientalizantes de la necrópolis de base de los dos túmulos, o mejor dicho círculos funerarios. Estos autores plantearon una primacía de la ocupación orientalizante del círculo funerario A sobre la del $\mathrm{B}$ que las determinaciones radiocarbónicas no apoyan. En efecto entre las dos tumbas de la

Trab. Prehist., 74, N. ${ }^{\circ}$ 2, julio-diciembre 2017, pp. 296-318, ISSN: 0082-5638

doi: $10.3989 /$ tp.2017.12196 
necrópolis de base atribuibles al Bronce Final que ahora disponen de fechas radiocarbónicas (A47, B18), la procedente del círculo funerario A pudiera resultar anterior a la del círculo funerario B. Sin embargo no se puede decir lo mismo de la ocupación orientalizante. Según los nuevos datos incluso parece plenamente posible que la ocupación orientalizante del círculo funerario B preceda la del círculo funerario A (Tab. 2; Fig. 3). Según ellos, tampoco se pueden mantener ya, evidentemente, las fechas absolutas atribuidas por Aubet et al. (1996: 146) a las tumbas de los dos monumentos: entre finales del siglo VIII y mediados del siglo VII para el círculo funerario A, y abarcando todo el siglo VII para el círculo funerario B. Esto no afecta a sus observaciones acerca de las diferencias entre los ajuares de los dos círculos funerarios que siguen siendo acertadas, pero deberán reinterpretarse a la luz de los nuevos resultados cronológicos.

También queda destacar que, a pesar de las complicaciones que supone la anomalía en la curva de calibración entre ca. 760 y $400 \mathrm{cal} \mathrm{AC,} \mathrm{la}$ única determinación radiocarbónica atribuible a una tumba de la fase II del túmulo B (B20) efectivamente demuestra una ligera tendencia hacia fechas más recientes que los correspondientes valores de la necrópolis de base, sin que quepa sacar de ello conclusiones más concretas.

No disponemos de determinaciones radiocarbónicas para la muy considerable cantidad de cerámicas, bronces y huesos calcinados encontrados en el relleno del túmulo B. Es posible que estos materiales fueran depositados voluntariamente y por primera vez en el túmulo B sin destruir tumbas de otro sector de la necrópolis. La práctica de fragmentar cuerpos y recipientes cerámicos es dominante en el paisaje funerario de Setefilla y, por lo tanto, la presencia de materiales desbaratados perfectamente cuadra con los rituales de fragmentación documentados en la necrópolis de base. Sin embargo, tampoco se puede descartar que, como seguramente sucede con las urnas redepositadas en la cubierta tumular del monumento A, esta impresionante cantidad de elementos individuales encontrados en el relleno de los dos túmulos proceda de la remoción de tierras de otros sectores de la necrópolis de base. En cualquier caso se trata de un fenómeno que merece una discusión más profunda.
La práctica de aprovechar las tierras procedentes de otras zonas de la misma necrópolis pero con diferencias tipológicas mínimas, se observa raramente en el ámbito del COSO, pero esta constatación está relacionada con el reconocimiento arqueológico de la zona. Por ejemplo, en el túmulo 1 de Las Cumbres se observó material cerámico numeroso y restos de huesos cremados (Ruiz Mata y Pérez 1989: 290) y en el túmulo L de Acebuchal los materiales contenidos en el relleno del túmulo eran considerablemente más antiguos que los materiales de su núcleo. M. ${ }^{a}$ E. Aubet, basándose en la descripción de J. Bonsor (1899: 27), argumenta que la tierra que formaba el túmulo L "contenía gran cantidad de huesos de animales, cenizas y fragmentos de cerámica, al parecer calcolítica, lo que significa que para su construcción se desbarató también alguna zona de necrópolis o de hábitat cercanos" (Aubet 1982a: 60). Sin embargo, y al contrario de lo que se observa en el túmulo A de Setefilla, no hay indicios de la destrucción de alguna tumba más antigua. M. ${ }^{a}$ R. Serna (1989: 52) retomó el tema proponiendo que los materiales anteriores estuvieran relacionados con la destrucción del estrato campaniforme inferior (cf. Sánchez 1994: 144).

Resulta entonces difícil descifrar el significado del acto de remoción de tumbas de otros sectores de la necrópolis de base y de su redeposición en la cubierta del túmulo A. Por un lado parece perfectamente posible que se trate de un acto pragmático, que no modifica el valor y la posición simbólica de las tumbas recolocadas. En esta perspectiva, la presencia de tumbas destruidas de la fase IV y otras encontradas en el relleno del túmulo seguiría la misma pauta de fragmentar los objetos (cf. Chapman 2000; Chapman y Gaydarska 2007) para subrayar el hecho de que la persona está muerta. De modo similar en Polonia durante la Edad Media y poco después se rompían armas, banderas, sellos, escudos y otros objetos personales pertenecientes al muerto de alto rango social (Chrościcki 1974). La destrucción intencional de elementos del ajuar funerario también consta en otros ámbitos culturales, como por ejemplo en el Bronce Inicial de Anatolia (Zimmermann 2010). Por consiguiente, sería de suponer que las tumbas desbaratadas de la fase IV y del relleno de túmulo A tienen el mismo valor y posición simbólica que los enterramientos de la necrópolis de base. Lo 
importante habría sido recibir un adecuado tratamiento funerario (incineración) y situarse dentro del espacio sagrado, es decir, dentro del espacio compuesto por el túmulo ${ }^{7}$. El estado fragmentario de algunos ajuares de la necrópolis de base pudiera favorecer esta interpretación.

Diversos hechos pudieran llevarnos a suponer una discriminación intencional favorable a la necrópolis de base respecto a otros sectores funerarios. Uno es el mayor grado de fragmentación en los ajuares de la cubierta tumular que en los de la necrópolis de base. Otro es el tratamiento más cuidadoso que recibieron las urnas redepositadas en la fase III del túmulo A, y probablemente procedentes de su círculo funerario antecesor, respecto a las encontradas en el relleno del mismo monumento, que habían de venir de otros sectores de la necrópolis. Resulta tentador hipotetizar que la destrucción de uno o varios círculos funerarios de la necrópolis de base, durante la remodelación que supuso la construcción de los túmulos y la colocación de cámaras centrales en algunos de ellos, refleje cambios en la estructura social de la población. Quizás algunos grupos de parentesco que utilizaban la necrópolis perdieron su posición anterior y su derecho a mantener un monumento funerario propio. Sin embargo no siempre resulta fácil integrar estas interpretaciones, basadas en los cambios que durante el período orientalizante se observan en la estructuración del espacio funerario, con informaciones derivadas de otros sectores del registro arqueológico (cf. Ruiz et al. 2007; Beba 2008: 131-133).

También hay que tener en cuenta que la remodelación, por lo menos en las fases II-IV del monumento A, bien puede coincidir con un momento en que el uso de la necrópolis de base ya se había abandonado por completo. Basándonos en las determinaciones radiocarbónicas no resulta posible fechar el final de la ocupación funeraria de ninguno de los dos túmulos investigados. Ahora bien, si fuera correcta la suposición de Aubet et al. (1996: 146) de que la ocupación atribuible al período orientalizante tan sólo habría durado un par de generaciones, sería rotundamente posible que, cuando se construyera la cámara central del túmulo A, la necrópolis de base ya estuviera en desuso. Las determinaciones radiocarbónicas

${ }^{7}$ Véase n. 3: Delgado 2002: 430-431. disponibles permitirían suponer sin más el fin de la ocupación de la necrópolis de base en fechas tan tempranas como el inicio del siglo VII a.C. Además, dado que S. Beba (2008: 132-133) ha podido defender con buenos argumentos un inicio de la construcción de cámaras como la del túmulo A sólo a partir de la primera mitad del siglo VII a.C., resultaría perfectamente plausible que esta remodelación en su momento ya no representara una interrupción del uso activo de la necrópolis de base.

Otra cuestión que hay que abordar en este contexto es la relación cronológica de los túmulos A y B con la estratigrafía del poblado de la Mesa de Setefilla. Ya más arriba se mencionó que la fase III del poblado (estratos XI-VI del Corte 1 y estratos XI-VIIa del Corte 3) se sincroniza con la ocupación orientalizante de la necrópolis por la cronotipología de sus materiales, mientras que la muy reducida gama de formas cerámicas asociadas a las sepulturas del Bronce Final (salvo las urnas bicónicas) dificulta una sincronización precisa con la estratigrafía del poblado. Evidentemente las sepulturas del Bronce Final deben corresponderse grosso modo con la fase II del poblado (estratos XIII-XIIa del Corte 3), pero no se puede concretar más (Aubet et al. 1983: 70-86). Una comparación a primera vista entre las determinaciones radiocarbónicas de las tumbas A5, A47 y B18 y las disponibles para el poblado parece sugerir la sincronización de las primeras con el intervalo temporal representado por el estrato XIIb (Tab. 3; Fig. 4). Sin embargo a la luz de la baja precisión de las últimas y de haberse fechado carbón vegetal no se puede justificar este tipo de conclusiones. En concreto, la cronología indicada por la determinación radiocarbónica procedente del estrato XIII (2029-1533 cal AC) difícilmente resulta atribuible a las cerámicas del Bronce Final de esa unidad estratigráfica. Sin nuevos datos también del poblado no se puede establecer en qué medida este aparente desfase se debe a la larga duración de la ocupación representada por el estrato XIII, o si la correspondiente determinación radiocarbónica se ve afectado por el efecto de la madera vieja.

Más arriba ya hemos mencionado la posible -breve- discontinuidad temporal entre la ocupación de la necrópolis de base y la construcción de la cámara del túmulo A. Hay que recordar que algunos investigadores también han defendido la

Trab. Prehist., 74, N. ${ }^{\circ}$ 2, julio-diciembre 2017, pp. 296-318, ISSN: 0082-5638

doi: 10.3989/tp.2017.12196 


\begin{tabular}{|c|c|c|c|c|c|c|c|}
\hline $\begin{array}{c}\text { Código } \\
\text { laboratorio }\end{array}$ & Estrato & $\begin{array}{c}\text { Fecha } \\
{ }^{14} \mathrm{C}\end{array}$ & \pm & $\begin{array}{l}\text { Fecha cal AC } \\
\text { intervalos } 1 \sigma\end{array}$ & Área relativa & $\begin{array}{l}\text { Fecha cal AC } \\
\text { intervalos } 2 \sigma\end{array}$ & Área relativa \\
\hline I-11067 & IX & 2490 & 90 & $\begin{array}{l}774-532 \\
530-517 \\
\end{array}$ & $\begin{array}{l}0,954820 \\
0,045180 \\
\end{array}$ & $797-407$ & 1,000000 \\
\hline I-11068 & XII A & 2560 & 125 & $825-513$ & 1,000000 & $\begin{array}{l}972-958 \\
939-394 \\
\end{array}$ & $\begin{array}{l}0,006497 \\
0,993503 \\
\end{array}$ \\
\hline I-11069 & XIII & 3470 & 95 & $\begin{array}{l}1906-1681 \\
1677-1665 \\
\end{array}$ & $\begin{array}{l}0,966580 \\
0,033420 \\
\end{array}$ & $\begin{array}{l}2029-1599 \\
1586-1533 \\
\end{array}$ & $\begin{array}{l}0,966676 \\
0,033324\end{array}$ \\
\hline I-11070 & XIV & 3520 & 95 & $\begin{array}{l}1966-1738 \\
1714-1697\end{array}$ & $\begin{array}{l}0,947547 \\
0,052453\end{array}$ & $\begin{array}{l}2133-2081 \\
2060-1622\end{array}$ & $\begin{array}{l}0,036909 \\
0,963091\end{array}$ \\
\hline
\end{tabular}

Tab. 3. Determinaciones radiocarbónicas del Corte 3 del poblado de la Mesa de Setefilla (según Aubet et al. 1983: 48-49; calibración con el programa Calib 7.0.4 [Stuiver et al. 2014] sobre la curva de calibración IntCal13 [Reimer et al. 2013]).

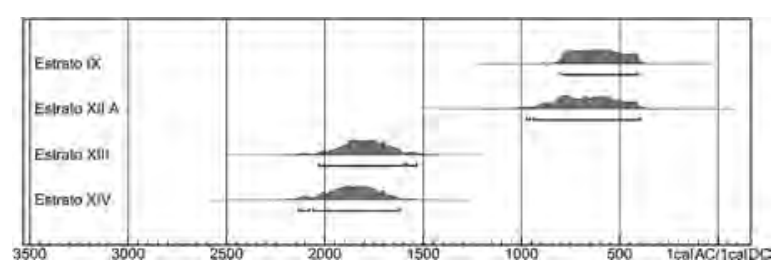

Fig. 4. Gráfico de las determinaciones radiocarbónicas calibradas (cal AC) del Corte 3 de la Mesa de Setefilla listadas en la tabla 3 (programa OxCal 4.2.4 [Bronk Ramsey 2013] sobre la curva de calibración IntCal13 [Reimer et al. 2013]).

idea de un profundo hiato durante el período entre 1100 y 850 a.C., o sea durante la mayor parte del Bronce Final (Caro 1989; Ruiz Gálvez 1990; Escacena y Belén 1991; Belén y Escacena 1995; Escacena 1995). Este hiato sería constatable tanto en la secuencia ocupacional del poblado de la Mesa de Setefilla como en toda la Baja Andalucía que habría experimentado un generalizado vacío poblacional (Aubet 1997: 166-168, Torres 1999: 39-40; Brandherm e. p.).

Aunque las nuevas determinaciones radiocarbónicas de la necrópolis de Setefilla no llenan por completo este supuesto vacío, el que se pueda demostrar que las mismas urnas bicónicas existen tanto a finales del II milenio (tumbas A5, A47, B18) como a inicios del siglo VIII cal AC (tumba A32) hace muy poco probable que hubiera un hiato en la ocupación humana de la zona. Dicho eso, si comparamos el número de sepulturas con urnas bicónicas (16 en el túmulo A y 6 en el túmulo $\mathrm{B}$ ) con el número de tumbas con urnas à chardon (34 en el túmulo $\mathrm{A}$ y 17 en el túmulo B), resulta obvio que la intensidad de la ocupación funeraria durante el Bronce Final (mínimo de 300 años) debió ser considerablemente menor que durante el Hierro Antiguo (máximo de 200 años), por lo menos en lo que concierne a este sector de la necrópolis.

De todas formas, hay que tener en cuenta que la separación cronológica entre estas dos formas de urnas cinerarias en el registro estratigráfico del poblado de la Mesa de Setefilla es menos clara de lo que parecen indicar las nuevas determinaciones radiocarbónicas de la necrópolis. Todavía coexisten en el estrato $\mathrm{X}$ del Corte 3 (Aubet et al. 1983: 88 fig. 33) y A. Delgado ${ }^{8}$, a partir de un estudio comparativo de los registros estratigráficos de la Baja Andalucía, sólo pudo afirmar que las urnas bicónicas "desaparecen en las secuencias estratigráficas conocidas a partir del siglo VIII a.C.".

Con el fin de establecer una base más firme para determinar la vigencia de las urnas bicónicas incluimos en nuestro programa de determinaciones radiocarbónicas una serie de contextos funerarios con este tipo de cerámica procedentes de otros yacimientos del sur y oeste peninsular. Su calibración confirma plenamente su atribución al intervalo entre el siglo XII y el IX cal AC, lo que mantiene la datación 798-732 cal AC de la tumba A32 de Setefilla, como la más reciente

\footnotetext{
${ }^{8}$ Véase n. 3: Delgado 2002: 423.
} 


\begin{tabular}{|c|c|c|c|c|c|c|c|}
\hline $\begin{array}{c}\text { Código } \\
\text { laboratorio }\end{array}$ & Contexto & $\begin{array}{c}\text { Fecha } \\
{ }^{14} \mathbf{C}\end{array}$ & \pm & $\begin{array}{c}\text { Fecha cal AC } \\
\text { intervalos 1 }\end{array}$ & Área relativa & $\begin{array}{c}\text { Fecha cal AC } \\
\text { intervalos 2 }\end{array}$ & Área relativa \\
\hline UBA-29079 & Rabadanes - S1 & 2774 & 30 & $\begin{array}{c}974-955 \\
943-894 \\
871-851\end{array}$ & $\begin{array}{c}0,206432 \\
0,634989 \\
0,158578\end{array}$ & $999-841$ & 1,000000 \\
\hline UBA-30686 & $\begin{array}{c}\text { Monte de São } \\
\text { Domingos - E2 }\end{array}$ & 2201 & 37 & $1000-912$ & 1,000000 & $\begin{array}{c}1046-888 \\
883-845\end{array}$ & $\begin{array}{c}0,927987 \\
0,072013\end{array}$ \\
\hline Beta-280041 & Souto - T1 & 2840 & 40 & $\begin{array}{c}1048-968 \\
964-931\end{array}$ & $\begin{array}{c}0,723054 \\
0,276946\end{array}$ & $1119-904$ & 1,000000 \\
\hline GrA-9270 & $\begin{array}{c}\text { Tanchoal de } \\
\text { Patudos (1) }\end{array}$ & 2230 & 50 & $1048-917$ & 1,000000 & $\begin{array}{c}1125-887 \\
884-844\end{array}$ & $\begin{array}{c}0,958250 \\
0,041750\end{array}$ \\
\hline GrA-9572 & $\begin{array}{c}\text { Tanchoal de } \\
\text { Patudos (2) }\end{array}$ & 2790 & 50 & $\begin{array}{c}1007-894 \\
866-856\end{array}$ & $\begin{array}{c}0,939824 \\
0,060176\end{array}$ & $\begin{array}{c}1072-1066 \\
1056-821\end{array}$ & $\begin{array}{c}0,005330 \\
0,994670\end{array}$ \\
\hline
\end{tabular}

Tab. 4. Determinaciones radiocarbónicas de sepulturas de incineración en urna del Bronce Final en el Suroeste de la Península Ibérica y zonas limítrofes. Los tipos de muestra fueron hueso quemado/colágeno (GrA-9270) y carbón vegetal (GrA-9572) en Tanchoal de Patudos (según Vilaça et al. 1999: tab. 1); hueso quemado/colágeno (Beta-280041) en Souto (según Delfino et al. 2014: 185) y hueso cremado / apatita en Monte de São Domingos (según Brandherm et al. 2017: 526) y Rabadanes. En la calibración se empleó el programa Calib 7.0.4 (Stuiver et al. 2014) sobre la curva de calibración IntCal13 (Reimer et al. 2013).

de esta serie (Tab. 4; Fig. 5) ${ }^{9}$. No obstante del efecto de la "meseta de Hallstatt" sobre las determinaciones radiocarbónicas asociadas a las urnas à chardon, resulta evidente que la transición entre estas dos formas emblemáticas de urnas cinerarias tuvo que tener lugar durante la primera mitad del siglo VIII cal AC, como ya Torres (1999: 175) defendió en su momento. La composición geográficamente diversa de nuestra muestra, con tres de los yacimientos aportando datos cronológicos acerca de la vigencia de las urnas bicónicas situadas en la cuenca baja y media del Tajo, así como la posibilidad de que los límites cronológicos de su empleo en el ámbito funerario variaran algo en el registro habitacional, hace que el intento de establecer una delimitación cronológica mas precisa mediante la estadística bayesiana tuviera poco sentido. El resultado, aunque fuera matemáticamente correcto, resultaría poco significativo en términos arqueológicos.

En cualquier caso, estos resultados ya no permiten dudar que la cronología convencionalmente atribuida a las urnas bicónicas, entre un momento

\footnotetext{
${ }^{9}$ Las dos determinaciones de Tanchoal de Patudos no se asocian directamente a urnas bicónicas, sino a un tipo de taza que se les asocia comúnmente, por ejemplo en el túmulo 1 de Souto, también incluido aquí (Delfino et al. 2014: tab. 15).
}

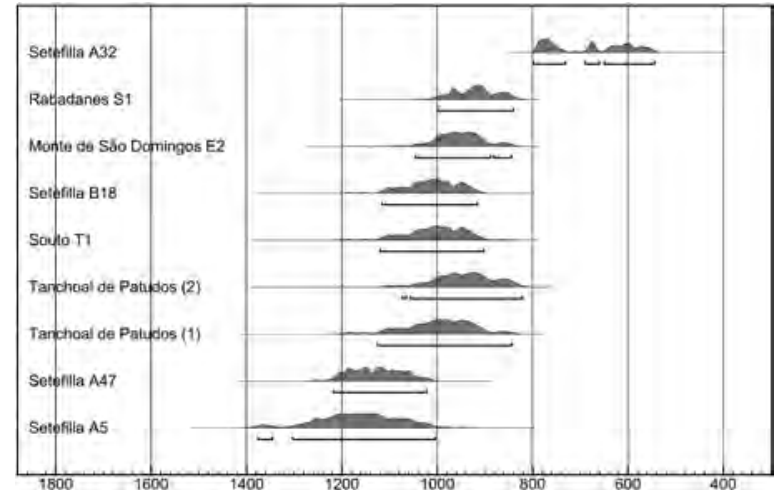

Fig. 5. Gráfico de las determinaciones radiocarbónicas calibradas (cal AC) de contextos funerarios con urnas bicónicas y formas asociadas; ejemplos de Setefilla listados en la tabla 2; ejemplos de otros yacimientos listados en la tabla 4 (programa OxCal 4.2.4 [Bronk Ramsey 2013] sobre la curva de calibración IntCal13 [Reimer et al. 2013]).

indeterminado del siglo $\mathrm{X}$ y mediados del siglo VIII a.C. (Torres 1996: 148 y 158, 1999: 171, 175; Pellicer y Escacena 2007: 12), resulta demasiado baja y que su inicio ahora se debe remontar al II milenio. Hacemos hincapié también en que la determinación radiocarbónica de la tumba B18 de Setefilla confirma la alta cronología para la técnica de decorar vasijas cerámicas con botones 


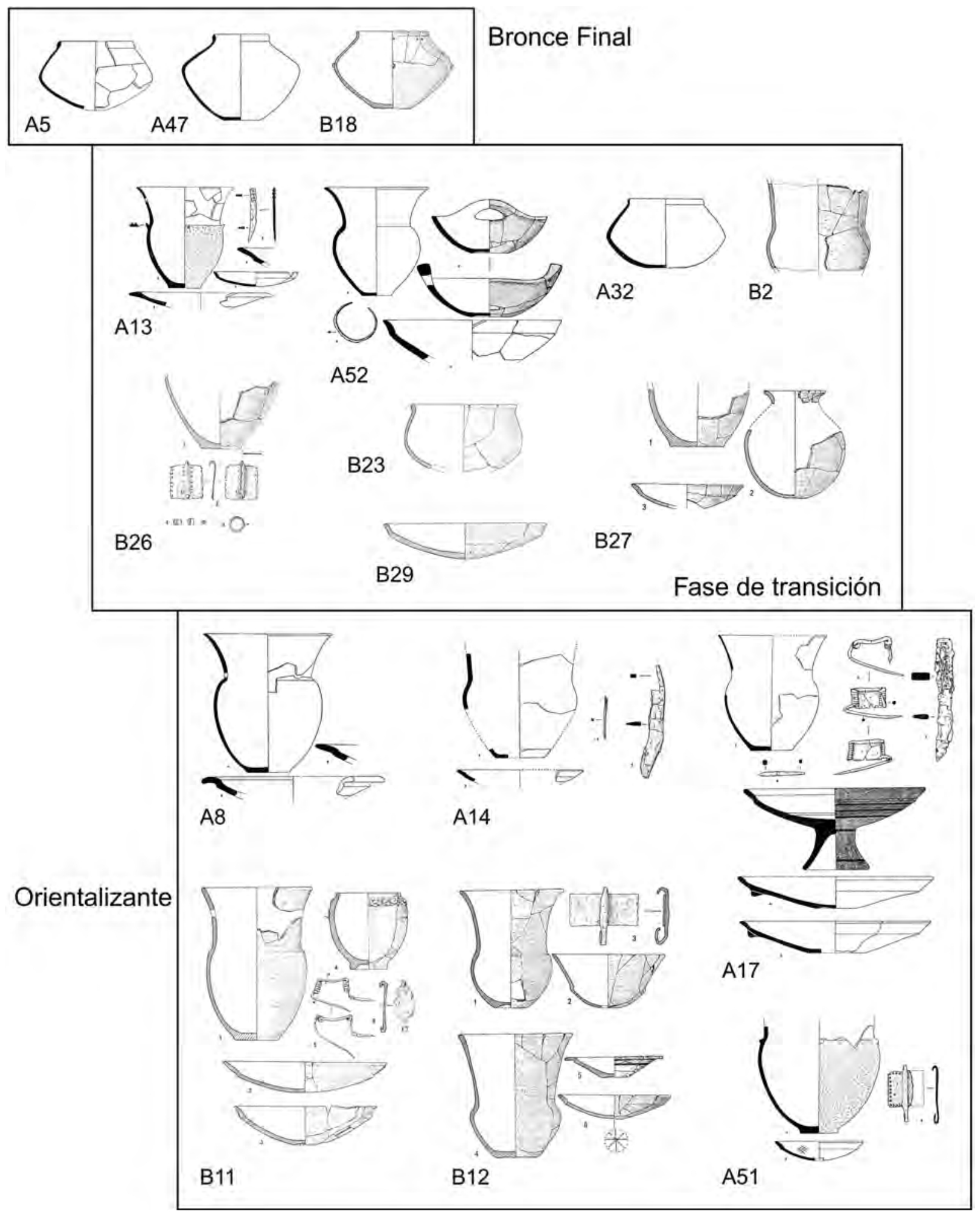

Fig. 6. Ajuares típicos del Bronce Final (1300/1200-840/820 cal AC) de la fase de transición (840/820-770/750 cal AC) y del periodo orientalizante (post-770/750 cal AC) en la necrópolis de Setefilla (Lora del Río, Sevilla) (según Aubet 1975: fig. 12,1; 14; 19; 20; 23; 46; 47; 50,1.3; Aubet 1978: fig. 6; 18; 19;22,2; 28,1;30;31;33). 
de bronce que ya indicaban los recientes hallazgos del Cerro del Castillo de Medellín (Jiménez y Guerra 2012: 88-91). Con anterioridad, a esta técnica se la habían atribuido fechas a partir del siglo VII (Pellicer 1987-88: 474), a partir de la segunda mitad del siglo IX (Lucas Pellicer 1995: 118; Dorado 2013: 15), o más genéricamente de los siglos X-VIII (Torres 2001: 278). Ahora parece evidente que sus orígenes también se deben remontar al II milenio.

Otra observación sugerente es que las dos únicas urnas, fechadas por nuestro programa de dataciones radiocarbónicas, que no se ajustan a ninguno de los dos tipos principales de urnas representadas en la necrópolis de base (bicónicas y à chardon) caen en la fase de transición entre los periodos cronológicos que representan (B23, B29). Eso plantea si la fase de transición entre las ocupaciones funerarias del Bronce Final y del Hierro Antiguo en Setefilla se caracteriza por la utilización creciente de tipos de vasos como urnas cinerarias que no se ajustan al canon de ninguna de estas dos fases. Esto es algo que no extrañaría durante un episodio de transformación, cuando también algunas normas sociales debieron experimentar cambios importantes (Fig. 6). Evidentemente, como la gran mayoría de las urnas distintas a los dos tipos principales quedan sin fechar, es imposible verificar esta idea. Quedará para futuros trabajos contrastarla con una base empírica más amplia.

Por último, si más arriba insistimos en que los enterramientos atribuibles al Bronce Final no contienen artefactos de tradición fenicia, también hay que hacer hincapié en que las determinaciones radiocarbónicas actualmente disponibles no permiten atribuir los ajuares que contienen estos elementos a un momento tardío dentro del Hierro Antiguo. Más bien parecen surgir ya a partir de los primeros momentos caracterizados por el uso de las urnas à chardon, caso de la cerámica indígena de tradición fenicia (Krueger et al. e. p.) y de los cuchillos afalcatados de hierro (Mancebo 2000), aunque la mayoría de las respectivas fechas caigan ya de pleno en la meseta de Hallstatt ${ }^{10}$. Con eso, la cultura material de la

\footnotetext{
${ }^{10}$ Entre las tumbas que proporcionaron determinaciones radiocarbónicas, la A8, A10, A14 y A31 según el estudio petrográfico contienen cerámica indígena de tradición fenicia y la A13, A14 y A17 cuentan con cuchillos afalcatados de hierro.
}

necrópolis de base, asociada a las urnas à chardon, es plenamente representativa de una fase inicial del fenómeno orientalizante, definido por prácticas culturales hibridas que posteriormente darán lugar a las nuevas expresiones funerarias que observamos en las denominadas "tumbas principescas" del Orientalizante Pleno (Krueger 2016: 110-111).

\section{CONCLUSIONES}

Las nuevas determinaciones radiocarbónicas demuestran que la cronología absoluta de los túmulos A y B de Setefilla amplían de modo considerable los límites que solían proponer los modelos cronológicos tradicionales, basados principalmente en la tipología de los vasos cerámicos. Se ha podido confirmar que las urnas bicónicas están arraigadas en el Bronce Final. Esto era algo que se suponía desde hace muchos años (por ejemplo ${ }^{11}$; Murillo et al. 2005: 30-31) pero, según las dataciones absolutas, ocurre bastante antes de lo esperado. Otro resultado novedoso de las fechas obtenidas a lo largo de nuestro programa de determinaciones radiocarbónicas es que el inicio de la ocupación orientalizante de la necrópolis de base del túmulo $\mathrm{B}$ no parece más reciente que la del túmulo $\mathrm{A}$ e incluso puede ser más antigua.

Al mismo tiempo ha quedado claro que ya no tiene mucho sentido la conceptuación de la ocupación funeraria del siglo VIII a.C. como expresión de un Bronce Final colonial. La cultura material asociada a las tumbas representa plenamente no sólo un Hierro Antiguo, sino también una fase inicial del fenómeno orientalizante, caracterizado por producciones indígenas de cerámicas de tradición fenicia.

Para los futuros trabajos sería importante abrir un nuevo sondeo en la Mesa de Setefilla, destinado sobre todo a obtener muestras orgánicas de vida corta para datar mejor los estratos arqueológicos y, en consecuencia, establecer una sincronización más concreta entre el poblado y la necrópolis de Setefilla. Las nuevas fechas del poblado y las secuencias de

11 Véase n. 3: Delgado 2002: 424.

Trab. Prehist., 74, N. ${ }^{\circ} 2$, julio-diciembre 2017, pp. 296-318, ISSN: 0082-5638

doi: $10.3989 /$ tp.2017.12196 
materiales bien fechadas podrían resolver los muchos problemas de índole crono-tipológica que aún presentan los artefactos de la necrópolis de Setefilla.

\section{AGRADECIMIENTOS}

Los autores del presente trabajo agradecen al Museo Arqueológico de Sevilla la posibilidad de extraer muestras del material óseo de Setefilla y a María Eugenia Aubet la oportunidad de continuar los trabajos con los materiales de Setefilla y todo su apoyo. José Luís Escacena y Laura Trellisó pusieron a nuestra disposición el material óseo de Rabadanes y João Luis Cardoso el del yacimiento de Monte de São Domingos. Agradecemos a Raquel Vilaça sus puntualizaciones sobre las muestras radiocarbónicas del Tanchoal dos Patudos. También queremos expresar nuestro agradecimiento a los dos evaluadores anónimos, cuyos comentarios y recomendaciones han sido de gran valor para nosotros. Se agradece también el valiosísimo consejo de Stephen Hoper en lo que concierne a la selección de las muestras. La realización de las analíticas no hubiera sido posible sin la colaboración del ${ }^{14} \mathrm{CHRONO}$ Centre de la Queen's University Belfast (http://www.chrono.qub.ac.uk/).

\section{BIBLIOGRAFÍA}

Almagro Gorbea, M.; Mederos, A.; Van der Plicht, J. y Torres Ortiz, M. 2008: Dataciones de Carbono-14 de la campaña de 1986". En M. Almagro Gorbea, A. J. Lorrio, A. Mederos y M. Torres (eds.): La necrópolis de Medellín. III: Estudio analíticos. IV: Interpretación de la necrópolis. V: El marco histórico de Medellin-Conisturgis. Bibliotheca Archaeologica Hispana 26-3, Real Academia de la Historia. Madrid: 875-877.

Aubet, M. ${ }^{a}$ E. 1973: "Materiales púnico-tartesios de la necrópolis de Setefilla en la Colección Bonsor". Boletín del Seminario de Estudios de Arte y Arqueología 39: 5-30.

Aubet, M. ${ }^{a}$ E. 1975: La necrópolis de Setefilla en Lora del Río, Sevilla. CSIC - Universidad de Barcelona. Barcelona.

Aubet, M. a E. 1976: "La cerámica púnica de Setefilla". Studia Archaeologica 42: 5-34.
Aubet, M. ${ }^{a}$ E. 1978: La necrópolis de Setefilla en Lora del Río, Sevilla (Túmulo B). CSIC - Universidad de Barcelona. Barcelona.

Aubet, M. ${ }^{a}$ E. 1980-1981: "Nuevos hallazgos en la necrópolis de Setefilla (Sevilla)". Mainake 2-3: 87-98.

Aubet, M. ${ }^{a}$ E. 1982a: "Cerámicas polícromas con motivos figurados de Setefilla (Sevilla)". En Homenaje a Conchita Fernández Chicarro. Ministerio de Cultura. Madrid: 211-226.

Aubet, M. ${ }^{\mathrm{a}}$ E. 1982b: "Los enterramientos bajo túmulo de Setefilla (Sevilla)". Huelva Arqueológica 6: 49-70.

Aubet, M. ${ }^{\text {a }}$ E. 1989: "La Mesa de Setefilla: la secuencia estratigráfica del Corte 1". En M. ${ }^{\mathrm{a}}$ E. Aubet (ed.): Tartessos. Arqueología protohistórica del Bajo Guadalquivir. Ausa. Sabadell: 297-338.

Aubet, M. ${ }^{a}$ E. 1995: "Aproximación a la estructura social y demográfica tartésica". Tartessos 25 años después 1968-1993. Actas del Congreso Conmemorativo de $V$ Simposio Internacional de la Prehistoria Peninsular (Cádiz 1993): 401-409. Jerez de la Frontera.

Aubet, M. ${ }^{a}$ E. 1997: "A propósito de una vieja estela". Saguntum 30: 163-172.

Aubet, M. ${ }^{\text {a E.; }}$ Barceló, J. A. y Delgado A. 1996: "Kinship, gender and exchange: the origins of Tartessian aristocracy". En A. M. ${ }^{a}$ Bietti Sestieri y V. Kruta (eds.): The Iron Age in Europe, XIII International Congress or Prehistoric and Protohistoric Sciences (Forlì, Italia 1996) Colloquia 12: 145-161. Forlì.

Aubet, M. ${ }^{a}$ E.; Serna, M. ${ }^{a}$ R.; Escacena, J. L. y Ruiz,

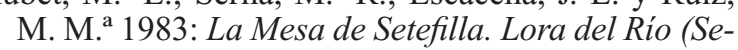
villa). Campaña de 1979. Excavaciones Arqueológicas en España 122, Ministerio de Cultura. Madrid.

Beba, S. 2008: Die tartessischen ,Fürstengräber' in Andalusien. Bochumer Forschungen zur ur- und frühgeschichtlichen Archäologie 1, Marie Leidorf. Rahden.

Belarte, M. ${ }^{a}$ C.; Malgosa, A.; Noguera, J.; Olmos, P. y Piga, G. 2013: "Las necrópolis protohistóricas tumulares de Cataluña meridional: el ejemplo de Sebes (Flix, Tarragona)". Trabajos de Prehistoria 70 (2): 295-314.

Belén Deamos, M. ${ }^{\mathrm{a}}$ y Escacena, J. L. 1995: "Acerca del horizonte de la Ría de Huelva. Consideraciones sobre el final de la Edad del Bronce en el Suroeste ibérico". En M. Ruiz Gálvez (ed.): Ritos de paso y puntos de paso. La Ría de Huelva en el mundo del Bronce Final europeo. Complutum Extra 5, Universidad Complutense. Madrid: 85-113.

Bonsor, J. 1899: "Les colonies agricoles pré-romaines de la Vallée du Bétis". Révue Archéologique 35, Ernest Leroux. París.

Bonsor, G.-E. 1931, The Archaeological Expedition along the Guadalquvir. The Hispanic Society of America. Nueva York.

Bonsor, J. y Thouvenot, R. 1928: Nécropole ibérique de Setefilla, Lora del Río (Sevilla). Bibliothèque de 
l'École des hautes études hispaniques 14, Féret et fils. Burdeos.

Brandherm, D. 2008a: "Erneut zur Datierung der ältesten griechischen und phönizischen Importkeramik auf der Iberischen Halbinsel”. Madrider Mitteilungen 49: 115-144.

Brandherm, D. 2008b: "Vasos a debate. La cronología del Geométrico griego y las primeras colonizaciones en Occidente". En S. Celestino, N. Rafel y X.-L. Armada (eds.): Contacto cultural entre el Mediterráneo y el Atlántico (siglos XII-VIII ane). La precolonización a debate. Serie Arqueológica 11, Escuela Española de Historia y Arqueología en Roma CSIC. Madrid: 93-106.

Brandherm, D. 2016: "Stelae, funerary practice, and group identities in the Bronze and Iron Ages of SW Iberia: a moyenne durée perspective". En J. T. Koch y B. Cunliffe (eds.): Celtic from the West 3. Atlantic Europe in the Metal Ages: questions of shared language. Oxbow Books. Oxford: 179-217.

Brandherm, D. en prensa: "Zum Übergang von der Mittel- zur Endbronzezeit im Südwesten der Iberischen Halbinsel". En T. Lachenal, C. Mordant, T. Nicolas y C. Véber (eds.): Le Bronze moyen et l'origine du Bronze final en Europe occidentale, de la Méditerranée aux pays nordiques (XVII ${ }^{\mathrm{e} \text { e }}$ $X I I I^{\text {ème }}$ siécle av. J.-C. Actes du colloque international "Bronze 2015" du 17 au 20 juin à Strasbourg. Maison Interuniversitaire des Sciences de l'Homme. Estrasburgo.

Brandherm, D.; Krueger, M. y Cardoso, J. L. 2017: "Um novo método para a datação absoluta de ossos humanos cremados: a cabana 2 do Monte de São Domingos (Malpica do Tejo, Portugal)". Estudos Arqueológicos de Oeiras 23, 2016-2017: 519-530.

Bronk Ramsey, C. 2009: "Bayesian analysis of radiocarbon dates". Radiocarbon 51: 337-360.

Bronk Ramsey, C. 2013: OxCal 4.2 [programa de calibración radiocarbónica]

Bronk Ramsey, C.; Dee, M.; Lee, S.; Nakagawa, T. y Staff, R. A. 2010: "Developments in the calibration and modeling of radiocarbon dates". Radiocarbon 52: 953-961.

Cardoso, J. L.; Caninas, J. C. y Henriques, F. 1998: "Duas cabanas circulares da Idade do Bronze Final do Monte de São Domingos (Malpica do Tejo, Castelo Branco)". Estudos Pré-Históricos 6: 325-345.

Caro, A. 1989: "Consideraciones sobre el Bronce Antiguo y Pleno en el bajo Guadalquivir". En M. ${ }^{a}$ E. Aubet (ed.): Tartessos. Arqueología protohistórica del Bajo Guadalquivir. Ausa. Sabadell: 85-120.

Chapman, J. 2000: Fragmentation in Archaeology. People, places and broken objects in the Prehistory of South Eastern Europe. Routledge. Londres - Nueva York.
Chapman, J. y Gaydarska, B. 2007: Parts and Wholes: Fragmentation in Prehistoric Context. Oxbow Books. Oxford.

Christen, J. A. y Litton, C. D. 1995: "A Bayesian approach to wiggle-matching". Journal of Archaeological Science 22: 719-725.

Chrościcki, J. A. 1974: Pompa funebris. Z dziejów kultury staropolskiej. PWN. Varsovia.

Cruz, D. J. 1997: "A necrópole de Bronze Final do 'Paranho' (Molelos, Tondela, Viseu)". Estudos PréHistóricos 5: 85-109.

Delfino, D.; Cruz, A.; Graça, A.; Gaspar, F. y Batista, A. 2014: "A problemática das continuidades e descontinuidades na Idade do Bronze do Médio Tejo português". En A. Cruz (ed.): A Idade do Bronze em Portugal: os dados e os problemas. Antrope, Série Monográfica 1, Instituto Politécnico de Tomar. Tomar: 146-201.

Dorado Alejos, A. 2013: "Nuevos datos para el estudio de las vasijas con apliques de bronce: un nuevo vaso en Cerro de los Infantes (Pinos-Puente, Granada)". Bastetania 1: 11-19.

Ellingham, S.; Thompson, T.; Islam, M. y Taylor, G. 2015: "Estimating temperature exposure of burnt bone: a methodological review". Science and Justice 55: 181-188.

Escacena, J. L. 1995: "La etapa precolonial de Tartessos. Reflexiones sobre el 'Bronce' que nunca existió". En Tartessos 25 años después 1968-1993. Actas del Congreso Conmemorativo de V Simposio Internacional de la Prehistoria Peninsular (Cádiz 1993): 179-214. Jerez de la Frontera.

Escacena, J. L. 2006: "Setefilla”. En J. M. ${ }^{a}$ Roldán (ed.): Diccionario Akal de la antigüedad hispana. Akal. Madrid: 861.

Escacena, J. L. y Belén Deamos, M. ${ }^{a}$ 1991: "Sobre la cronología del horizonte fundacional de los asentamientos tartésicos". Cuadernos del Suroeste 2: 9-42.

García Sanjuan, L. y Odriozola Lloret, C. 2012. "La cronología radiocarbónica de la Edad del Bronce (c. 2200-850 cal ANE) en el Suroeste de la Península Ibérica". En J. Jiménez Ávila (ed.): Sidereum Ana II. El río Guadiana en el Bronce Final. Anejos de Archivo Español de Arqueología 62, CSIC - Junta de Extremadura. Mérida: 363-387.

Gilboa, A. 2013: “À-propos Huelva: a reassessment of 'early' Phoenicians in the West”. En J. M. Campos y J. Alvar (eds.): Tarteso. El emporio del metal. Almuzara. Córdoba: 311-342.

Jiménez Ávila, J. y Guerra Millán, S. 2012: “El Bronce Final en Medellín. Estudio preliminar del corte SMRO”. En J. Jiménez Ávila (ed.): Sidereum Ana II. El Guadiana en el Bronce Final. Anejos de Archivo Español de Arqueología 62, CSIC. Madrid: 65-110.

Kalb, P. y Höck, M. 1980: "Cabeço da Bruxa, Alpiarça (Distrikt Santarém). Vorbericht über die Grabung im Januar und Februar 1979". Madrider Mitteilungen 21: 91-104. 
Krueger, M. 2016: "Local response to the early Phoenician presence in western Andalusia: the case of material culture from Setefilla". En L. Donnellan, V. Nizzo y G.-J. Burgers (eds.): Contexts of Early Colonization. Papers of the Royal Netherlands Institute in Rome 64, Palombi. Roma: 105-111.

Krueger, M.; Brandherm, D.; Bartkowiak, M. y Niedzielski, P. en prensa: "Material culture and chronology of western Andalusia in the Late Bronze Age and Early Iron Age". En S. Stoddart, B. Dimova, J. Joy y M. Gleba (eds.): Craft and Production in the European Iron Age. Oxbow Books. Oxford.

Lanting, J. N. y Brindley, A. L. 1999: "Fechando hueso cremado: la base científica". Trabajos de Prehistoria 56 (2): 137-140.

Lanting, J. N.; Aerts-Bijma, A. T. y Van der Plicht, J. 2001: "Dating of cremated bone". Radiocarbon 43: 249-254.

López Castro, J. L.; Ferjaoui, A.; Mederos Martín, A.; Martínez Hahnmüller, V. y Ben Jerbania, I. 2016: "La colonización fenicia inicial en el Mediterráneo Central: nuevas excavaciones arqueológicas en Utica (Túnez)". Trabajos de Prehistoria 73 (1): 68-89.

Lorrio, A. J. 2008: Qurénima. El Bronce Final del Sureste de la Península Ibérica. Real Academia de la Historia. Madrid.

Lucas Pellicer, M. ${ }^{\text {a }}$ R. 1995: “Cerámicas con apliques de metal". Boletín de la Asociación Española de Amigos de la Arqueología 35: 107-122.

Maier, J. 1999: Jorge Bonsor (1855-1930). Un académico correspondiente de la Real Academia de la Historia y la Arqueología Española. Real Academia de la Historia. Madrid.

Mancebo Dávalos, J. 2000: “Análisis de los objetos metálicos en el período orientalizante y su conexión con el mundo fenicio. Los cuchillos afalcatados". En Actas del IV Congreso Internacional de Estudios Fenicios y Púnicos (Cádiz 1995): 1825-1834. Cádiz.

Manning, S. W. y Weninger, B. 1992: "A light in the dark: archaeological wiggle matching and the absolute chronology of the close of the Aegean Late Bronze Age". Antiquity 66: 636-663.

Murillo Redondo, J. F.; Morena López, J. A. y Ruiz Lara, D. 2005. "Nuevas estelas de guerrero procedentes de las provincias de Córdoba y de Ciudad Real". Romula 4: 7-46.

Naysmith, P.; Scott, E. M.; Cook, G. T.; Heinemeier, J.; Van der Plicht, J.; Van Strydonck, M.; Bronk Ramsey, C.; Grootes, P. M. y Freeman, S. P. H. T. 2007: "A cremated bone intercomparison study". Radiocarbon 49: 403-408.

Pellicer Catalán, M. 1987-88: “La cerámica a mano del Bronce reciente y del orientalizante en Andalucía occidental". Habis 18-19: 461-483.

Pellicer Catalán, M. y Escacena Carrasco, J. L. 2007: "Rabadanes. Una nueva necrópolis de época tartésica en el Bajo Guadalquivir". Lucentum 26: 7-21.
Reimer, P. J.; E. Bard, E.; Bayliss, A.; Beck, J. W.; Blackwell, P. G.; Bronk Ramsey, C.; Buck, C. E.; Cheng, H.; Edwards, R. L.; Friedrich, M.; Grootes, P. M.; Guilderson, T. P.; Haflidason, H.; Hajdas, I.; Hatté, C.; Heaton, T. J.; Hoffmann, D. L.; Hogg, A. G.; Hughen, K. A.; Kaiser, K. F.; Kromer, B.; Manning, S. W.; Niu, M.; Reimer, R. W.; Richards, D. A.; Scott, E. M.; Southon, J. R.; Staff, R. A.; Turney, C. S. M. y Van der Plicht, J. 2013: "INTCAL13 and marine INTCAL13 radiocarbon age calibration curves $0-50,000$ years Cal BP”. Radiocarbon 55 (4): 1869-1887.

Reimer, P.; Hoper, S.; McDonald, J.; Reimer, R.; Svyatko, S. y Thompson, M. 2015: The Queen's University Belfast Laboratory Protocols used for AMS Radiocarbon Dating at the ${ }^{14}$ CHRONO Centre: Scientific Dating Report. Research Report Series 5-2015, English Heritage. Swindon.

Roberts, B.; Uckelmann, M. y Brandherm, D. 2013: "Old Father Time: the Bronze Age chronology of Western Europe". En H. Fokkens y A. Harding (eds.): The Oxford Handbook of the European Bronze Age. Oxford University Press. Oxford: 17-41.

Ruiz, A.; Molinos, M. y Rísquez C. 2007: "El espacio funerario en el proceso de construcción del modelo aristocrático ibérico en la Alta Andalucía". En M. Molinos y A. Ruiz (eds.): El hipogeo ibero del Cerrillo de la Compañía de Hornos (Peal de Becerro, Jaén). Junta de Andalucía - Universidad de Jaén. Jaén: 115-143.

Ruiz Gálvez, M. 1990: "Canciones del muchacho viajero". Veleia 7: 79-103.

Ruiz Mata, D. y Pérez, C. J. 1989: “El túmulo 1 de la necrópolis de Las Cumbres (Puerto de Santa María, Cádiz)". En M. ${ }^{a}$ E. Aubet (ed.): Tartessos: Arqueología protohistórica del Bajo Guadalquivir. Ausa. Sabadell: 287-295.

Sánchez Andreu, M. 1994: Las necrópolis tumulares de los Alcores (Sevilla). Universidad de Cádiz. Cádiz.

Serna, M. ${ }^{a}$ R. 1989: "El vaso campaniforme en el Valle del Guadalquivir". En M. ${ }^{\mathrm{a}}$ E. Aubet (ed.): Tartessos. Arqueología protohistórica del Bajo Guadalquivir. Ausa. Sabadell: 47-84.

Stuiver, M.; Reimer, P. J. y Reimer, R. W. 2014: CALIB 7.0 [programa de calibración radiocarbónica]

Taylor, R. E.; Stuiver, M. y Reimer, P. J. 1996: “Development and extension of the calibration of the radiocarbon time scale: archaeological applications". Quaternary Science Reviews 15: 655-668.

Thompson, T.; Gauthier, M. y Islam, M. 2009: "The application of a new method of Fourier Transform Infrared Spectroscopy to the analysis of burned bone". Journal of Archaeological Science 36: 910-914.

Thompson, T.; Islam, M.; Piduru, K. y Marcel, A. 2011: "An investigation into the internal and external variables acting on crystallinity index using Fourier Transform Infrared Spectroscopy on unaltered and burned bone". Palaeogeography, Palaeoclimatology, Palaeoecology 299: 168-174. 
Torres Ortiz, M. 1996: "La cronología de los túmulos A y B de Setefilla. El origen del rito de la cremación en la cultura tartésica". Complutum 7: 147-162.

Torres Ortiz, M. 1998: "La cronología absoluta europea y el inicio de la colonización fenicia en Occidente. Implicaciones cronológicas en Chipre y el Próximo Oriente". Complutum 9: 49-60.

Torres Ortiz, M. 1999: Sociedad y mundo funerario en Tartessos. Bibliotheca Archaeologica Hispana 3, Real Academia de la Historia. Madrid.

Torres Ortiz, M. 2001: "La cerámica a mano con decoración de botones de bronce. Una aportación al estudio de la alfarería tartésica del Bronce Final". Spal 10: 275-281.

Trellisó Carreno, L. 2001: “La acción del fuego sobre el cuerpo humano: la antropología física y el análisis de las cremaciones antiguas". Cypsela 13: 89-100.

Vilaça, R.; Cruz, D. J. y Gonçalves, A. H. B. 1999: "A necropole de Tanchoal dos Patudos (Alpiarça, Santarém)". Conimbriga 38: 5-29.

Zimmermann, T. 2010: "Verbogen, zerschlagen, zerhackt - Spuren ekstatischer Inszenierungen in frühbronzezeitlichen Gräbern Anatoliens". Colloquium Anatolicum 9: 367-380. 